for Katja and Alfred 


\title{
Bee pollination of strawberries on different spatial scales - from crop varieties and fields to landscapes
}

\author{
Dissertation \\ zur Erlangung des Doktorgrades \\ der Fakultät für Agrarwissenschaften \\ der Georg-August-Universität Göttingen
}

vorgelegt von

Björn Kristian Klatt

geboren in Bielefeld

Göttingen, im Februar 2013 
D 7

1. Referentin/Referent: Prof. Dr. Teja Tscharntke

2. Korreferentin/Korreferent: Prof. Dr. Stefan Vidal

Tag der mündlichen Prüfung: 13. Februar 2013 


\section{TABLE OF CONTENTS}

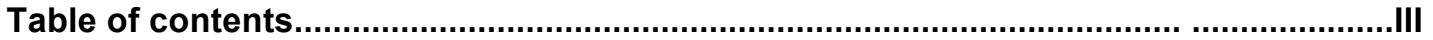

\section{Chapter 1}

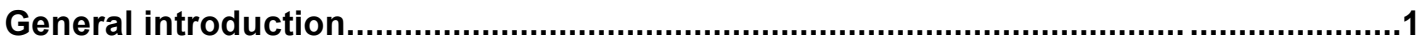

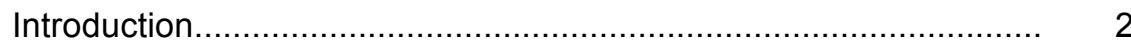

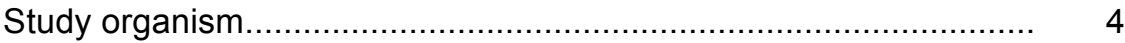

Study region $\&$ sites..................................................... 5

Research questions \& chapter outline................................... 7

Results \& conclusions.................................................... 8

References..................................................................... 10

\section{Chapter 2}

Bee pollination improves crop quality, shelf life and

commercial value

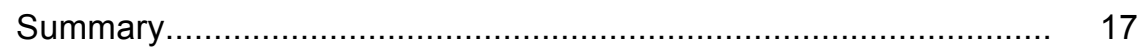

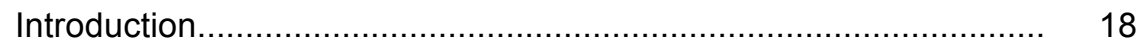

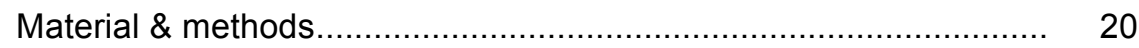

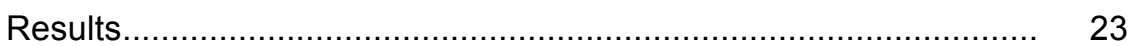

Discussion................................................................ 27

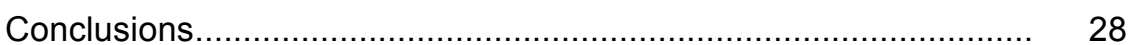

Acknowledgements................................................... 29

References............................................................. 29

Supplementary information................................................... 34

\section{Chapter 3}

Enhancing crop shelf life with bee pollination.

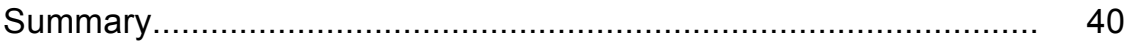

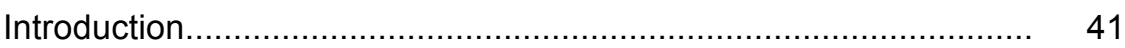

Material \& methods............................................................ 42 


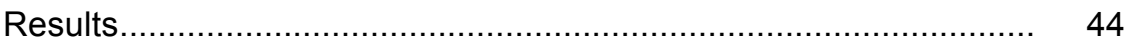

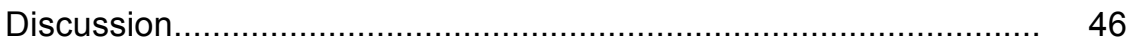

Conclusions..................................................................... 47

Acknowledgements................................................... 48

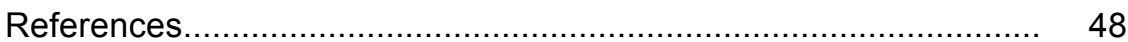

\section{Chapter 4}

Flower volatiles of crop varieties and bee responses..............................................52

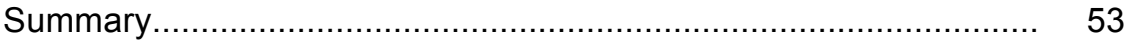

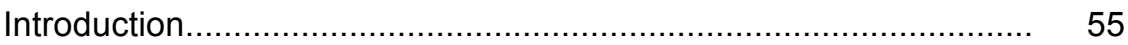

Material \& methods.......................................................... 57

Results..................................................................... 60

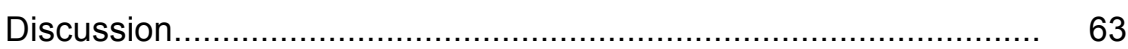

Conclusions................................................................... 66

Acknowledgements...................................................... 70

References................................................................... 70

\section{Chapter 5}

Context-dependent importance of honeybee vs. wild bee pollination from crop field edges to centres.

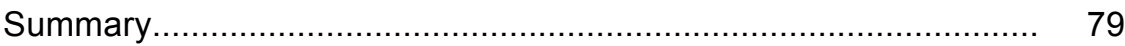

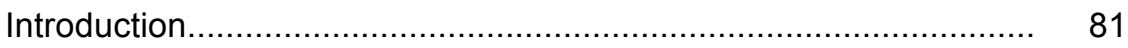

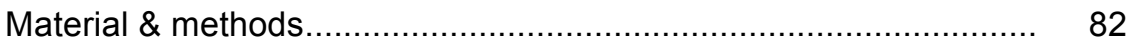

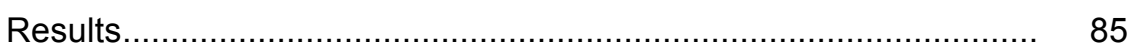

Discussion............................................................. 89

Conclusions................................................................. 91

Acknowledgements............................................................ 92

References............................................................. 92

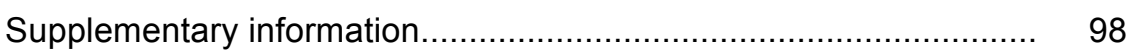




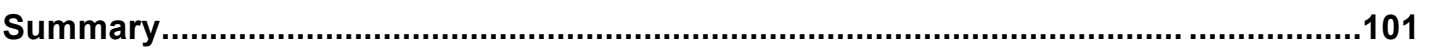

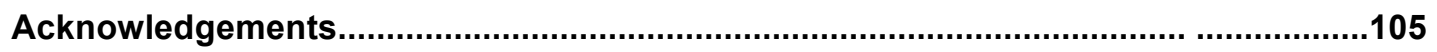

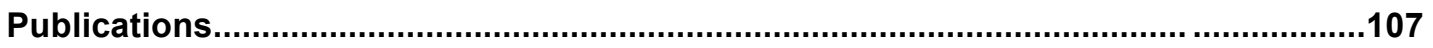

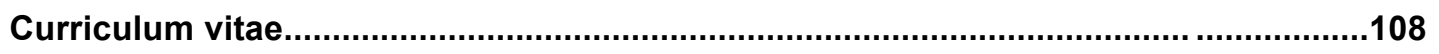


Chapter 1

General introduction 
INTRODUCTION. Pollination is one of the most important ecosystem services based on its contribution to more than one third of world crop production (Klein et al. 2007). Estimated $75 \%$ of world crop species (Klein et al. 2007) and $84 \%$ of european crop species (Ghazoul 2005) are dependent on or at least profit from animal pollination. Hence, pollination has been frequently confirmed as an ecosystem service of high commercial and social importance (Costanza et al. 1997; Klein et al. 2007; Gallai et al. 2009; Winfree, Gross \& Kremen 2011). Growing demands for food and energy (Godfray et al. 2010) and simultaneously increasing cultivation of pollination dependent crops (Aizen et al. 2008, Lautenbach et al. 2012) highlight the need to maintain or even improve future pollination services (Aizen et al. 2008, Lautenbach et al. 2012). Summarizing the main questions of future pollination research (Mayer et al. 2011) emphasize that pollination research is still at the beginning and our knowledge about crop pollination is scarce at various scales. What do we really know about crop pollination, its main facetts and drivers and where are important limits?

Current knowledge about the benefits of crop pollination is almost exclusively focused on increasing fruits set and fruit size, resulting in higher yields mainly due to bee pollination (Free 1993; Klein et al. 2007; Jauker et al. 2012; Holzschuh, Dudenhöffer \& Tscharntke 2012). But the results from only few available studies (Al-Attal, Kasrawi \& Nazer 2003; Cuevas, Hueso \& Puertas 2003; Dag \& Mizrahi 2005; Shin, Park \& Kim 2007; Freihat et al. 2008; Choi et al. 2009; Gajc-Wolska et al. 2011) suggest, that the benefits of pollination, including fruit quality and shelf life, are yet far from being fully explored.

Bees, which are the most important crop pollinators (Roubik 1995; Klein et al. 2007; Dötterl \& Vereecken 2010) are still endangered by anthropogenic impacts, 
especially from agricultural intensification (Potts et al. 2010). It has been little explored, how bees are attracted by various crop varieties (Rodriguez-Saona et al. 2009), although the availability of varieties is rapidly increasing (CPVO 2012), simultaneously to agricultural intensification. Recent declines of honeybees (CoxFoster et al. 2007; Anderson \& East 2008) demonstrate the importance of pollinaton services offered by wild bees for the future, but clearly less is known about the general mechanisms of attraction for solitary wild bees (Dötterl \& Vereecken 2010). In general, it is still debated wether honeybees, wild bees, or even few generalist species provide adequate pollination services on crops and how this is affected by the surrounding landscape. Previous findings are contradictory, but have so far been conducted on field scales (Albano et al. 2009) or at distinct field locations (Andersson, Rundlöf \& Smith 2012) without considering effects arising from different locations on the field.

This emphasizes that most studies that have been conducted on pollination so far are limited to specific scales (Potts et al. 2010). Formulating effective conservation strategies for the maintenance of pollination services requires the connection of comprehensive knowledge about pollination (Potts et al. 2010). Hence, the current work is focused on the main facets and drivers of pollination at different spatial scales, from varieties over fields to landscapes. It adresses unknown benefits of bee pollination on strawberry fruits from different varieties including the so far not considered aspect of shelf life, pollinator attraction between varieties due to chemical cues and the role of honeybees, wild bees and overall bee diversity for the pollination efficiency of strawberry flowers at different field locations. 
STUDY ORGANISM. Strawberry (Fragaria $x$ ananassa DUCH.) is the most frequently grown soft fruit in the world with an increasing production quantity worldwide (FAOSTATS 2012). More than 1000 varieties are currently available at the market (CPVO 2012) and usually a couple of different varieties are grown on each commercial field. Strawberry varieties differ in several traits as flowering and harvest time and date, resistance against diseases and taste as well as fruit size and quantity (CPVO 2012), but also in their dependence on insect pollination (Connor \& Martin 1973; Connor 1975; Zebrowska 1998). In general, most strawberry varieties are self compatible and thus accessible for wind and self pollination (Free 1993). But stigmas become receptive before the antheres of the same flower releases pollen and thus allogamy is favoured (Free 1993).

During their visits, insect pollinators transfer conspecific pollen between plants as well as allocate clumped and aggregated pollen homogenous over the receptacles, increasing the number of fertilized achenes (Svensson 1991). Achenes are the true "nut-fruits" on the surface of the strawberry as an aggregated fruit (Free 1993). They are known to produce growth factors that enhance cell progeny and size (Nitsch 1950; Csukasi et al. 2011) and thus strawberries are known to have weight increases and less deformations in dependence on the variety, if insect pollination is provided (Free 1998). Strawberries are mainly pollinated by bees, with honey bees being most frequent (Free 1993). In addition, several wild bee species visit strawberry flowers with their abundance and species composition depending on the country (Free 1993). In greenhouses, the genus Osmia spp. Panz. has been confirmed as a suiteable pollinator for strawberries (Chagnon, Gingras \& de Oliveira 1993), which is also known to be an efficient pollinator of strawberries under field conditions (Nye \& Andersson 1974; Albano et al. 2009). Strawberry is an excellent model organism for 
pollination experiments. Its metabolism is well investigated (see chapters 2 and 3 as well as references therein) and as it is an aggregated fruit, pollination success can be assessed on the individual fruit level (Andersson et al. 2012).

STUDY REGION \& SITES. All experiments and surveys were conducted in Germany, on an experimental strawberry field, in a greenhouse and on conventionally managed fields for commercial strawberry selling, respectively.

The first study (chapter two) was conducted on an experimental field. It was located adjacent to the greenhouse of the Agroecology group (Agroecology, Department of Crop Sciences, University of Goettingen, Goettingen, Germany) in the eastern part of the city of Göttingen. It was surrounded by hedges from two sides and grassy margins at the other sides. The entire area is surrounded by hedges and dominated by open space that is partly used for experiments and surveys. Large areas remain unused all over the year with several flowering plant species. Five honey bee hives (Apis mellifera L.), several trap nests dominated by Osmia bicornis L., as well as nests of bumble bees (e. g. Bombus terrestris L.) and other ground nesting bees (e. g. Andrena spp. F., Lasioglossum spp. Curt.) were located near the strawberry field. The second study (chapter three) was partly conducted on the expermiental field and on an commercial strawberry field. Latter is located in the vicinity of Göttingen with a size of more than 4 ha. The surrounding landscape is dominated by arable land and pastures with a proportion of semi-natural habitats (mostly hedges and forest strips) of about $8 \%$. The field is divided into different parts, concerning to novel plantings each year. Alltogether, eight varieties are grown on the field with the current study focussing on the variety Yamaska. 
For the third study (chapter four), the first part of the experiment was conducted in an climate controlled, isolated part at the greenhouse of the Buesgen-Institute (Department of Forest Zoology and Forest Conservation, University of Goettingen, Goettingen, Germany). The second part of this study was conducted at the same commercial strawberry field used for study two (chapter three), but on the varieties Honeoye and Sonata.

The fourth study (chapter five) was conducted on commercial strawberry fields located between the city of Northeim, Lower Saxony, the Southern Harz, Lower Saxony and the city of Kassel, Northern Hesse. This region is dominated by intensive agricultur, interspersed by variously extended areas of semi-natural habitats (see Thies \& Tscharntke 1999 and Steffan-Dewenter et al. 2002 for details). The north to south extension of the study area was $50 \mathrm{~km}$ and $75 \mathrm{~km}$ from east to west. Aim of the study was to analyse landscape effects on pollen loads of bees and the effects of bee diversity and abundance on strawberries. Hence, strawberry fields were selected based on a landscape gradient of surrounding semi-natural habitats ranging from homogenous landscapes with about $2 \%$ of semi-natural habitats to more heterogenous landscapes with up to $14 \%$ of semi-natural habitats on a radius of 1000 m (ArcGIS, ESRI, München, Germany). Semi-natural habitats were mainly forest, orchards and hedges and tree lines adjacent to crop fields and roads as well as successional areas (unmanaged grassland interspersed with bushes and small trees). Fallows and flowering stripes were not present in the selected landscapes. Strawberry fields were at least $2 \mathrm{~km}$ seperated and had a minimum size of $1.5 \mathrm{ha}$. 
RESEARCH QUESTIONS \& CHAPTER OUTLINE. The current work is focused on the overall benefits and main drivers of crop pollination by bees. It is giving a broad perspective on the indluence of bee pollination on strawberry fruits and the underlying mechansims of bee pollination at different spatial scales such as varieties, fields and landscapes.

Bee pollination of strawberries. Relationships between bee pollination, marketability and post-harvest quality of strawberries in dependence on different varieties were analysed. In detail, the following questions were adressed (separated according to chapters 2 and 3 ):

- Does bee pollination improve the commercial value and post-harvest quality of strawberry fruits due to higher pollination succcess compared to wind and self pollination?

- How does strawberry varieties differ on the effects of the three pollination treatments?

- What is the influence of pollination mediated commercial grades on firmness and fruit decay of strawberries during storage.

Strawberry pollination by bees on different spatial scales. Effects from various disciplines influencing strawberry pollination by bees between varieties, field positions and landscapes were analysed. In detail, the following questions were adressed (separated according to chapters 4 and 5): 
- Do strawberry varieties differ in the emission of flower volatile compounds?

- How do females of the solitary wild bee $O$. bicornis, a frequently strawberry pollinator, respond to the found compounds?

- Do differences in the emission of flower volatile compounds between strawberry varieties lead to diverse visitation rates of $O$. bicornis females under field conditions?

- Which of the landscape dependent bee parameters abundance, species richness, Shannon-diversity and Evenness is the best predictor of strawberry pollination?

- Does the relative importance of these parameters vary depending on the location in the field?

- How does the performance of A. mellifera, the most abundant pollinator species in strawberry fields, influence these parameters and their effects on strawberry yield?

RESULTS \& CONCLUSIONS. Bee pollination improved the commercial value and post-harvest quality of strawberries depending on varieties. Bee pollinated fruits were heavier and could be sorted into higher commercial grades due a better shape than fruits resulting from wind and self pollination across all varieties. These improvements led to a generally higher commercial value of bee pollinated fruits. Most varieties showed their fruits to have an elongated shelf life, intensified red colour as well as lower sugar-acid ratios from bee pollination, thereby enhancing the 
post-harvest quality of strawberries. These effects were confirmed as a result of bee pollination, by higher amounts of fertilized achenes, the true "nut"-fruits of the strawberry, compared to wind and self pollinated fruits.

Detailed analysis on the relationship between pollination and shelf life showed that bee pollinated strawberries and strawberries from higher commercial grades had a higher number of fertilized achenes. Higher commercial grades improved firmness and fruit weight and lead to less decay during storage time. Firmness, fruit weight and decay were highly correlated. Hence, bee pollination resulted in higher commercial grades and elongated the shelf life of strawberries compared to fruits from minor grades, resulting from wind pollination.

Strawberry varieties differed in the emission quantity, not quality, of various flower volatile compounds, while several, for strawberry varieties so far unknown compounds were found. Females of the solitary wild bee O. bicornis, a frequent strawberry pollinator, responded on all emitted compounds but in different intensity. On a commercial strawberry field, O. bicornis females visited the variety Sonata more frequently than the variety Honeoye, presumably due to higher emissions of the most important flower volatile compounds.

At the field scale, strawberry pollination was dependent on either, honeybees and wild bees, with effects changing between field locations. Strawberry fruit weight was best explained by Evenness and less by Shannon-diversity, while the effects of bee species richness and abundance were inconsistent. An even bee community benefited strawberry fruit weight at the field edge, while the most dominant pollinator A. mellifera, presumably due to higher conspecific pollen loads, was most important at the field centre, leading to contrasting effects of Evenness. In general, Evenness was negatively correlated to the proportion of honeybees. Pollen from 
oilseed rape (Brassica napus L.) formed the highest fraction of heterospecific pollen and was negatively correlated to the proportion of strawberry pollen.

In conclusion, bee pollination is a key factor for strawberry quantity and in particular quality and appeared to be driven by varying effects between spatial scales with context-dependent contributions of both, honeybees and wild bees. Hence, on one side, pollination is of higher importance for crop production as investigated so far and has the potential to countervail increasing demands on high quality food. On the other side, crop pollination is dependent on the entire bee community as well as influenced by various spatial factors and thus shows up to be complex process, which is highly sensitive to disturbances. This emphasizes that continuing anthropogenic threats as agricultural intensification will have extensive impacts on world food security. Hence, considering a broader perspective on the benefits and requirements of crop pollination as shown in this work, might improve so far insufficient conservation strategies to maintain this highly important ecosystem service for the future.

\section{REFERENCES}

Aizen, M.A., Garibaldi L.A., Cunningham, S.A. \& Klein, A.-M. (2008) Long-term global trends in crop yield and production reveal no current pollination shortage but increasing pollinator dependency. Current Biology, 18, 15721575 .

Al-Attal, Y.Z., Kasrawi, M.A. \& Nazer, I.K. (2003) Influence of pollination technique on greenhouse tomato production. Journal of Agricultural and Marine Sciences, 8, 21-26. 
Albano, S., Salvado, E., Duarte, S., Mexia, A. \& Borges, P.A.V. (2009) Pollination effectiveness of different strawberry floral visitors in Ribatejo, Portugal: selection of potential pollinators. Part 2. Advances in Horticultural Science, 23, 246-253.

Anderson, D. \& East, I.J. (2008) The latest buzz about colony collapse disorder. Science, 319, 724-725.

Andersson, G.K.S., Rundlöf, M. \& Smith, H.G. (2012) Organic farming improves pollination success in strawberries. PLoS ONE, 7, e31599.

Chagnon, M., Gingras, J. \& de Oliveira, D. (1993) Complementary aspects of strawberry pollination by honey and indigenous bees (Hymenoptera). Journal of Economic Entomology, 86, 416-420.

Choi, Y.H., Kang, N.J., Park, K.S., Chun, L., Cho, M.W., Um, Y.C. \& You, H.Y. (2009) Influence of fruiting methods on fruit characteristics in cherry tomato. Korean Journal of Horticultural Science \& Technology. 27, 62-66.

Connor, L.J. \& Martin, E.C. (1973) Components of pollination of commercial strawberries in Michigan. HortScience, 8, 304-306.

Connor, L.J. (1975) The role of cultivar in insect pollination of strawberries. Proceedings of the 3rd International Symposium on Pollination, 149-154.

Costanza, R., d'Arge, R., de Groot, R., Farber, S., Grasso, M., Hannon, B., Limburg, K., Naeem, S., O'Neill, R.V., Paruelo, J., Raskin, R.G., Sutton, P., \& van dem Belt, M. (1997) The value of the world's ecosystem services and natural capital. Nature, 38, 253-260.

Cox-Foster, D.L. Conlan, S., Holmes, E.C., Palacios, G., Evans, J.D., Moran, N.A., Quan, P.-L., Briese, T., Hornig, M., Geiser, D.M., Martinson, V., van Engelsdorp, D., Kalkstein, A.L., Drysdale, A., Hui, J., Zhai, J., Cui, L., Hutchison, 
S.K., Simsons, J.F., Egholm, M., Pettis, J.S. \& Lipkin, W.I. (2007) A metagenomic survey of microbes in honey bee colony collapse disorder. Science, 318, $283-287$.

CPVO - Community Plant Variety Office of the European Union (2012). http:// www.cpvo.europa.eu/main/en.

Cuevas, J., Hueso, J.J. \& Puertas, M. (2003) Pollination requirements of loquat (Eriobotrya japonica Lindl.), cv. 'Algerie'. Fruits, 58, 157-165.

Csukasi, F., Osorio, S., Gutierrez, J.R., Kitamura, J., Giavalisco, P., Nakajima, M., Fernie, A.R., Rathjen, J.P., Botella, M.A., Valpuesta, V. \& Medina-Escobar, N. (2011) Gibbellerin biosynthesis and signalling during developement of the strawberry receptacle. New Phytologist, 191, 376-390.

Dag, A. \& Mizrahi, Y (2005) Effect of pollination method on fruit set and fruit characteristics in the vine cactus Selenicereus megalanthus ("yellow pitaya"). The Journal of Horticultural Science and Biotechnology, 80, 618-622.

Dötterl, S. \& Vereecken, N.J. (2010) The chemical ecology and evolution of beeflower interactions: a review and perspectives. Canadian Journal of Zoology, 88, 668-697.

FAOSTATS - Food and Agricultural Organaziation of the United Nations (2012). Statistical Devision. http://faostat.fao.org/default.aspx.

Free, J.B. (1993) Insect Pollination of Crops. Academic Press, London, UK.

Freihat, N.M., Al-Ghzawi, A. A.-M., Zaitoun, S. \& Alqudah, A. (2008) Fruit set and quality of loquats (Eriobotrya japonica) as effected by pollinations under subhumid Mediterranean. Scientia Horticulturae, 117, 58-62. 
Gajc-Wolska, J., Kowalczyk, K., Mikas, J., Drajski, R. (2011) Efficiency of cucumber (Cucumis sativus L.) pollination by bumblebees (Bombus terrestris). Acta Scientiarum Polonorum, 10, 159-169.

Gallai, N., Salles, J.-M., Settele, J. \&Vaissiere, B.E. (2009) Economic valuation of the vulnerability of world agriculture confronted with world pollinator decline. Ecological Economics, 68, 810-821.

Ghazoul, J. (2005) Buzziness as usual? Questioning the global pollination crisis. Trends in Ecology and Evolution, 20, 367-373

Godfray, H.J.C. (2010) Food security: the challenge of feeding 9 billion people. Science, 327, 812-818.

Holzschuh, A., Dudenhöffer, J.-H. \& Tscharntke T. (2012) Landscapes with wild bee habitats enhance pollination, fruit set and yield of sweet cherry. Biological Conservation, 153, 101-107.

Jauker, F., Bondarenko, B., Becker, H.C. \& Steffan-Dewenter, I. (2012) Pollination efficiency of wild bees and hoverflies provided to oilseed rape. Agricultural and Forest Entomology, 14, 81-87

Klein, A.-M., Vaissiere, B.E., Cane, J.H., Steffan-Dewenter, I., Cunningham S.A., Kremen, C. \& Tscharntke, T. (2007) Importance of pollinators in changing landscapes for world crops. Proceedings of the Royal Society B, 274, 303-313.

Lautenbach, S., Seppelt, R., Liebscher, J. \& Dormann, C.F. (2012) Spatial and temporal trends of global pollination benefit. PLOS ONE, 7, e35954.

Mayer, C., Adler, L., Armbruster, W.S., Dafni, A., Eardley, C., Huang, S.-Q., Kevan, P.G., Ollerton, J., Packer, L., Ssymank, A., Stout, J.C. \& Potts, S.G. (2011) Pollination ecology in the 21st century: key questions for future research. Journal of Pollination Ecology, 3, 8-23. 
Nitsch, J.P. (1950) Plant hormones in the developement of fruits. The Quarterly Review of Biology, 28, 33-57.

Nye, W.P. \& Andersson, J.L. (1974) Insect pollinators frequenting strawberry blossoms and the effect of honey bees on yield and fruit quality. Journal of the American Society for Horticultural Science, 99, 40-44.

Potts, S.G., Biesmeijer J.C., Kremen, C., Neumann, P., Schweiger, O. \& Kunin, W.E. (2010) Global pollinator declines: trends, impacts and drivers. Trends in Ecology and Evolution, 25, 345-353.

Roubik, D.W. (1995) Pollination of cultivated plants in the tropics. Food and agriculture organization of the United Nations, Rome, Italy. Bulletin 118.

Rodriguez-Saona, C., Parra, L., Quiroz, A. \& Isaacs, R. (2011) Variation in highbush blueberry floral volatile profiles as a function of pollination status, cultivar, time of day and flower part - implications for flower visitation by bees. Annals of Botany, 107, 1377-1390.

Shin, Y.S., Park, S.D. \& Kim, J.H. (2007) Influence of pollination methods on fruit development and sugar contents of oriental melon (Cucumis melo L. cv. Sagyejeol-Ggul) Scientia Horticulturae, 112, 88-392.

Steffan-Dewenter, I., Münzenburg, U., Buerger, C., Thies, C. \& Tscharntke, T. (2002) Scale-dependent effects of landscape context on three pollinator guilds. Ecology, 83, 1421-1432.

Svensson, B. (1991) The importance of honeybee-pollination for the quality and quantity of strawberries (Fragaria $x$ ananassa) in Central Schweden. Acta Horticulturae 288, 260-264.

Thies, C. \& Tscharntke, T. (1999) Landscape structure and biological control in agroecosystems. Science, 285, 893-895. 
Winfree, R., Gross, B.J. \& Kremen, C. (2011) Valueing pollination services to agriculture. Ecological Economics, 71, 80-88.

Zebrowska, J. (1998) Influence of pollination modes on yield components in strawberry (Fragaria x ananassa Duch.). Plant Breeding, 117, 255-260. 


\section{Chapter 2}

Bee pollination improves crop quality, shelf life and commercial value

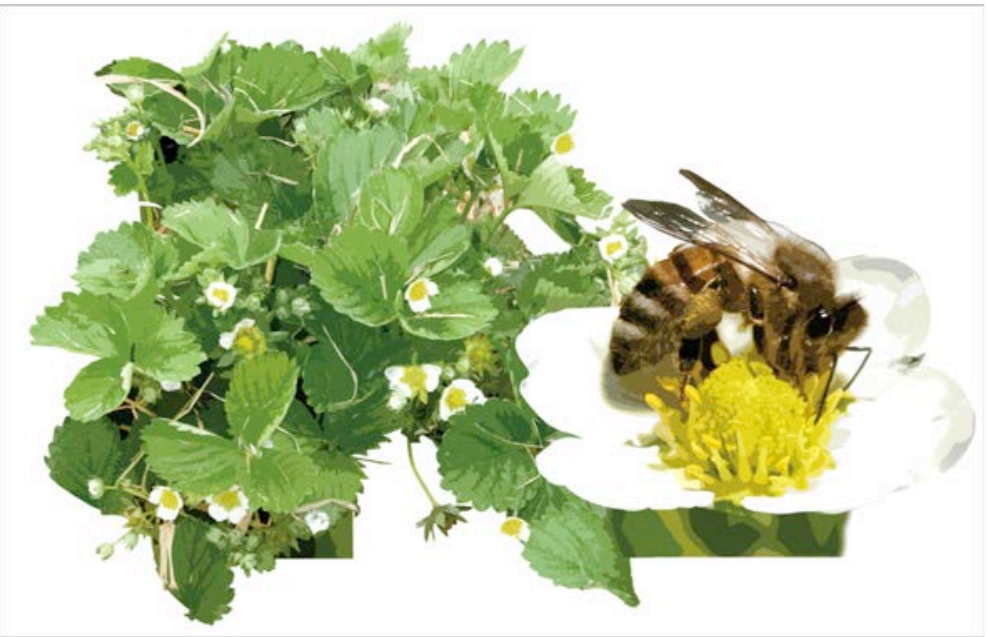




\section{SUMMARY}

1. Pollination is known to improve the yield of most crop species and a third of global crop production, but comprehensive benefits including crop quality are still unknown.

2. This is why the commercial value of crop pollination is underestimated, which is particularly alarming in times of agricultural intensification continuing to diminish pollination services.

3. In this study, exclusion experiments on strawberries showed bee pollination, mainly conducted by wild bees, to improve fruit quality, quantity and market value compared to wind and self pollination.

4. Bee pollinated fruits were heavier, had less malformations and reached higher commercial grades.

5. They were firmer, thus improving the commercially important shelf life and had increased redness and reduced sugar-acid-ratios.

6. These comprehensive findings demonstrate bee pollination to be a hitherto underestimated but vital determinant of fruit quality.

KEY-WORDS: colour, commercial grades, ecosystem services, firmness, market value, post-harvest quality, strawberry, wild bees, yield 
INTRODUCTION. Awareness of global biodiversity losses and declines of ecosystem services such as pollination (Potts et al. 2010) has influenced international politics, shown by the COP strategic plan of the CBD meeting in Nagoya in 2010, but was disregarded by the common agricultural policy (CAP) of the EU. Pollination is known to increase quantity and thereby the commercial value of most crop species (Klein et al. 2007; Gallai et al. 2009). But at the same time, modern agriculture is still contributing to the decline of pollination through intensified management (Potts et al. 2010). Benefits of pollination may include several features of crop quality that have been rarely analysed. Crop features allowing longer storage and thereby, reducing postharvest losses in supermarkets and households are a major challenge worldwide (Tscharntke et al. 2012). In this study, we expand our knowledge of the underestimated benefits of bee pollination by experimentally quantifying its impacts on crop quantity, quality, shelf life and market value. We used strawberries (Fragaria $x$ ananassa DUCH.), a worldwide increasing crop (FAOSTATS 2012), as a model system.

In strawberries, flowers are ordered in consecutive flowering periods, becoming smaller over time (Free 1993). Varieties are self-compatible in most cases and stigmas become receptive before the antheres of the same flower release pollen, so that allogamy is favoured. Bee pollination increases strawberry weight and shape, but effects depend on varieties (Free 1993). Recent findings about new metabolic processes in strawberries support the idea, that pollination may also impact the shelf life of strawberries (Given, Venis \& Grierson 1988; Roussos, Denaxa \& Damvakaris 2009; Villareal, Martinez \& Civello 2009; Csukasi et al. 2011). Due to high fruit sensitivity to fungal infections and mechanical injuries, strawberry fruits have a short shelf life (Roussos et al. 2009). More than $90 \%$ of fruits can be non- 
marketable after only four days in storage (Hernandez-Munoz et al. 2006). Several studies have focused on the potential elongation of the shelf life of strawberries with modified storage procedures (Civello et al. 1999; Sanz et al. 1999; HernandezMunoz et al. 2006; Colla, Sobral \& Menegalli 2006; Caner, Aday \& Demir 2008), highlighting its economically huge importance. Shelf life and pathogenic susceptibility of strawberry fruits are mostly related to their firmness (HernandezMunoz et al. 2006), but also surface colour and sugar-acid-ratios are involved (Civello et al. 1999; Sanz et al. 1999; Hernandez-Munoz et al. 2006; Colla et al. 2006; Caner et al. 2008). Fruit colour further determines the first impression of consumers influencing their purchase behaviour (Caner et al. 2008). The colour of strawberry fruits results mainly from anthocyanin pigments (Given et al. 1988; Seeram 2008), which protect the fruit against UV-radiation and oxidative substances making fruits healthier for humans (Seeram 2008). The colour of fruits has never been related to animal pollination and only few studies report a relation of pollination to firmness (Al-Attal, Kasrawi \& Nazer 2003; Shin, Park \& Kim 2003; Gajc-Wolska et al. 2011) and sugar-contents (Shin et al. 2003; Cuevas, Huesco \& Puertas 2003; Dag \& Mizrahi 2005; Freihat et al. 2008; Choi et al. 2009) of fruits. Hence, comprehensive economic gains of bee pollination on strawberries and other fruits are largely unknown and in particular, the potential effect on commercially important parameters of the overall fruit quality has not yet been explored.

We set up a field experiment with nine commercially important strawberry varieties. The influence of self, wind and bee pollination on strawberry fruits was analysed using exclusion treatments. We calculated the commercial value of each fruit based on commercial grades (European Commission 2007) and fruit weight while accounting for market value differences between harvest months (AMI 2012). Further, 
we assessed pollination success, quantified by the number of fertilized achenes per fruit, as well as the influence of bee pollination on fruit colour, sugar-acid ratios and firmness, affecting shelf life. We fitted linear mixed effects models with pollination treatments as fixed effect levels and with random effects allowing treatment slopes and intercept to vary among varieties. To test whether all or individual pollination treatments had a main effect across all varieties or predominating variety differences imped differences between pollination treatments, models with unpooled and successively pooled treatment levels as well as models without treatment as a fixed effect were compared (Bolker et al. 2009) using AICc and likeliness (Burnham \& Anderson 2002), respectively.

MATERIAL \& METHODS. Nine commercially important strawberry varieties of Fragaria x ananassa DUCH. (Darselect, Elsanta, Florence, Honeoye, Korona, Lambada, Salsa, Symphony, Yamaska) were planted on an experimental field in 2008. The field was subdivided in twelve plots and nine rows per plot planted with 18 plants of a single variety per row. All varieties were present in all plots. The sequence of the rows within the plots was randomized. The field was surrounded by two further rows of strawberries to weaken edge effects. Experiments were conducted in 2009 in the first yield year using exclusion treatments on two plants per variety and plot. All buds of a plant were covered with Osmolux®-bags (Pantek, Montesson, France) to allow only self pollination (self pollination treatment), gaze bags (mesh width $0.25 \mathrm{~mm}$ ) to allow self and wind pollination (wind pollination treatment) or remained uncovered to allow additional insect pollination (bee pollination treatment), respectively. Bags were removed shortly after fruit set and at 
least 50 fruits per variety and treatment were harvested at maturity. All analyses except the titratable acid content were conducted at the same day of harvesting to avoid influence on post harvest quality due to water loss and metabolic procedures. The commercial value of each fruit was calculated based on commercial grades and fruit weight (BA2001 S, Sartorius, Goettingen, Germany) while accounting for value differences between harvest months (AMI 2012).

Fruits were sorted into commercial grades, due to aberrations in shape, colour and size, following the official trade guidelines (European Commision 2007). Fruits without or with only slight aberrations were sorted into grade extra/one, whereas distinct aberrations lead to a classification in grade two. Non-marketable fruits had strong colour and shape aberrations. Following the above mentioned Commission Regulation, grades Extra and One can be treated separately, but are used combined in practice. Proportions of fruits for each commercial grade and pollination treatment were calculated across all varieties (Fig. $2 A$ ) and also separately for each variety (Table S3).

Fruits were bisected and firmness was measured at the center of each half according to Sanz et al. (1999) with the following modifications: the texture analyzer (TxT2, Stable Micro System, Surrey, England) was fitted with a $5 \mathrm{~mm}$ diameter probe and a $25 \mathrm{~kg}$ compression cell, while a maximum penetration of $4 \mathrm{~mm}$ was used.

Colourimetric analysis were applied according to Caner et al. (2008) at two opposite sides of the center of each fruit in the Lab-colour space using a portable colourimeter (CR-310 Chromameter, Konica Minolta, Badhoevedorp, The Netherlands). The total soluble solids are strongly correlated to the total sugar content of a solution and were measured using a handheld refractometer (HRH30, Krüss, Hamburg, Germany). Measurements for each fruit were conducted twice and repeated when 
the values differed more than 0.2 Brix. Fruit solutions were freeze-dried (Epsilon 240, Christ, Osterode, Germany) and all samples from the same plant were pooled and milled. To account for an average water content of $82 \%$, which was analysed on a sample of 250 fruits, $0.18 \mathrm{~g}$ of each freeze dried sample was diluted in $20 \mathrm{ml}$ destilled water and titrated according to Caner et al. (2008).

At least eight fruits from each variety and treatment were used to analyse the number of fertilized achenes per fruit, which represent pollination success. Each fruit was blended in $100 \mathrm{ml}$ distilled water for two minutes (Speedy Pro GVA 1, Krups, Offenbach, Germany). Fertilized achenes are heavier than water and sink to the bottom whereas aborted achenes are lighter and accumulate at the water surface. Fertilized achenes were counted (Contador, Pfeuffer, Kitzingen, Germany) after drying for 48 hours at 85 degrees Celsius.

Mean values were calculated in cases of repeated measurements per fruit. We fitted linear mixed-effects models with random effects allowing treatment slopes and intercept to vary among varieties (Bolker et al. 2009). To account for space and time errors and unbalance in the data, the random part was completed by two further terms: plot variety and plant as well as flowering period as a crossed random effect. Response variables were commercial value per fruit, fruit weight, number of fertilized achenes, firmness and surface colour values (red colour, brightness, yellow colour). In the models with sugar-acid-ratio as response variable, only plot and variety were used to complete the random part, because sugar-acid-ratios were calculated based on arithmetic means per plant.

Bee, wind and self pollination treatments were used as fixed effect levels. To test whether pollination treatments differ and whether there was a main effect of all pollination treatments across all varieties, a model with unpooled treatment levels 
(full model), models with successively pooled treatment levels and a model without treatment as fixed effect were compared (Bolker et al. 2009) using second order Akaike's Information Criterion (AICc) and likeliness (Burnham \& Anderson 2002). This allowed us to test whether treatment in general, only specific treatment levels, or no treatment had an effect on the response variables. Latter case indicated that variety differences dominated treatment effects. Residuals were inspected for constant variance, and transformations were used to account for non-normality and heterogeneity, where necessary. Main effect values and parameter estimates were extracted from the model and used for plotting after back transformation.

RESULTS. Strawberry flowers were mainly pollinated by wild bees (75.8\%), while Apis mellifera L. (24.2\%) was less abundant (Table S1). The solitary wild bee Osmia bicornis L. $(38,9 \%)$ was the most abundant pollinator, while other wild bee species accounted to less than $5 \%$ of the bee community.

Bee pollination resulted in strawberry fruits with the highest commercial value (Fig. 1). On average, bee pollination increased the commercial value per fruit by $38.6 \%$ compared to wind pollination and by $54.3 \%$ compared to self pollination. Fruits resulting from wind pollination had a $25.5 \%$ higher market value than self pollinated fruits. Pollination treatments were stronger than differences between varieties and thus had a main effect across all varieties (Table S2). Our results suggest that altogether bee pollination contributed more than 1.06 billion US-Dollars to a total of 2.76 billion US-Dollars made with commercial strawberry selling in the EU in 2009 (FAOSTATS 2012). Price and marketability of strawberries depend on commercial grades of fruit quality (shape, size and colour) (European Commission 
2007). Especially malformations are a common problem affecting strawberry price and marketability (Ariza et al. 2010). Our experiment showed that bee pollination reduced malformations and thus enhanced marketability in all varieties except the variety Symphony (Fig. 2a; Table S3). The highest proportion of bee pollinated fruits was assigned to the best grade extra/one, whereas non-marketable fruits

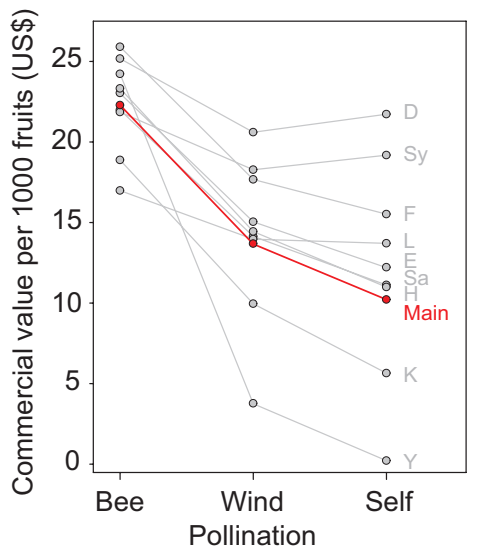

Fig. 1. Bee pollination improved the commercial value of strawberry fruits across all varieties. Commercial values were calculated in US-Dollar per fruit and extrapolated to 1000 fruits for a better relationship to market situations. Displayed values were extracted from model estimates and back transformed. Grey points display values of varieties values (see abbreviations below), red points display the main effect. Lines are shown for better visualisation of related points. Solid red lines for the main effect indicated, that pollination treatments were stronger than differences between varieties and thus had a main effect across all varieties (see Table S2 for AICc and likeliness values). Abbreviations in alphabetical order: D., Darselect; E., Elsanta; F., Florence; Main, main effect; H., Honeoye; K., Korona; L., Lambada; Sa., Salsa; Sy., Symphony; Y., Yamaska.

formed the smallest fraction. In contrast, wind and self pollination led to high proportions of non-marketable fruits. Bee pollination did not only enhance fruit shape, but also fruit weight compared to wind and self pollination (Fig. 2b). Bee pollinated fruits were on average $11.0 \%$ heavier than wind pollinated and $30.3 \%$ heavier than self pollinated fruits. Pollination treatments were stronger than differences between varieties and thus had a main effect across all varieties (Table S2).

According to our results, bee pollination significantly impacted the shelf life of strawberries by improving their firmness (Fig. 3a). The firmness values of each treatment and variety were related to shelf life, measured as days until $50 \%$ of fruits 

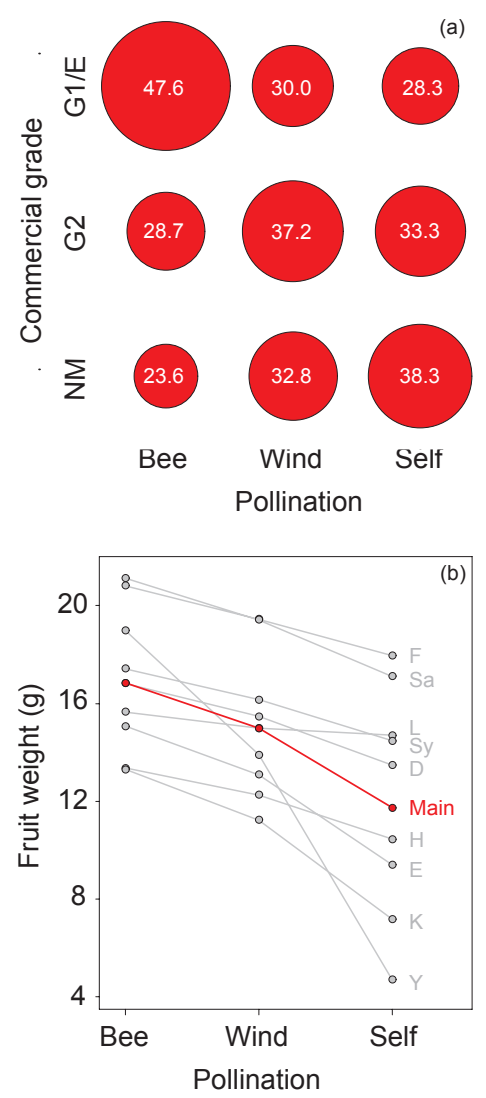

Fig. 2. Bee pollination improved commercial grades and weight of strawberry fruits. (a) Commercial grades. Fruit proportions (values within bubbles) were calculated for each commercial grade in dependence on pollination treatments (see Table S3 for division into varieties). (b) Weight of strawberry fruits. G1/E = Commercial grade one/extra; G2 = Commercial grade two; NM = nonmarketable. Further details and abbreviations are explained in the legend of Fig. 1. had been lost due to surface and fungal decay (Fig. S1). Higher firmness resulting from beepollination potentially elongated the shelf life of strawberry fruits about twelve hours compared to wind pollination and more than 24 hours compared to self pollination. Pollination treatments had a main influence on shelf life across all varieties (Table S2). Varieties producing fruits with high firmness benefitted most from bee pollination.

Bee pollinated fruits further had a more intense red colour compared to fruits resulting from wind and self pollination for most varieties (Fig. 3b). Self pollinated fruits of the varieties Lambada and Symphony showed the most intense red colour in the self pollination treatment. The bee pollination treatment differed from both other pollination treatments across all varieties, whereas strong variety differences imped a difference between wind and self pollination treatments (Table S2). The brightness of bee and wind pollinated fruits was similar and highly correlated to yellowness (Fig. S2). Thus bee pollination resulted in bright fruits with a more intense red colour than wind pollination fruits, whereas self 
pollinated fruits were darker and less red (Fig. 3b, S2). Senescence of strawberries is not only related to losses in firmness and colour changes, but also to increasing sugar-acid-ratios. Bee pollinated fruits had generally a lower sugar-acid-ratios compared to wind- and self pollinated fruits across all varieties (Fig. 3c), but fruits of the varieties Elsanta and Symphony had a higher sugar-acid-ratio with bee pollination. The difference between wind and self pollination remained variety dependent (Table S2), whereas the sugar-acid-ratio of fruits resulting from bee pollination differed to both other treatments across all varieties.

Pollination success was related to the number of fertilized achenes dependent on pollination treatments. Bee pollination was much more efficient than wind and self pollination, resulting in a higher number of fertilized achenes per fruit across all
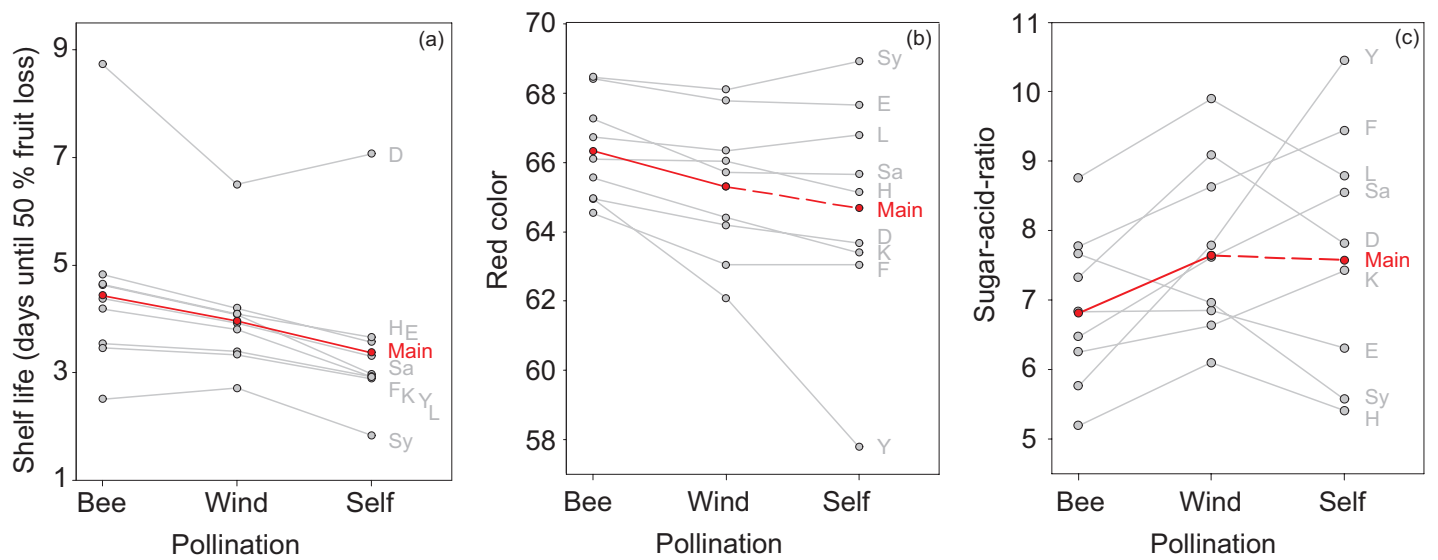

Fig. 3. Bee pollination improves the post-harvest quality of strawberries. (a) Shelf life in days until $50 \%$ fruit loss was calculated from firmness values that were related to published data on firmness decreases during storage (Hernandez-Munoz et al. 2006). (b) Red colour intensity. (c) Sugar-acid-ratios. Red lines for the main effect are dashed when pollination treatments did not significantly differ, indicating stronger variety effects than pollination treatments (see Table S2 for AICc and likeliness values). Further details and abbreviations are explained in the legend of Fig. 1. 
varieties (Fig. 4; Table S2). Bee pollinated fruit on average increased the number of fertilized achenes about $26.8 \%$ compared to wind pollination and $61.7 \%$ compared to self pollination. Wind pollinated fruits had $47.7 \%$ higher number of fertilized achenes than fruits resulting from self pollination. This confirms our findings to be true effects of bee pollination.

DISCUSSION. We found bee pollination to play a key role for several features of the quality and quantity of marketable strawberry fruits, including more intensive colour, longer shelf life, less malformations and greater fruit weight.

Our results showed strawberries to be mainly pollinated by wild bees. This contrasts to earlier findings, where honeybees were the most abundant pollinator of

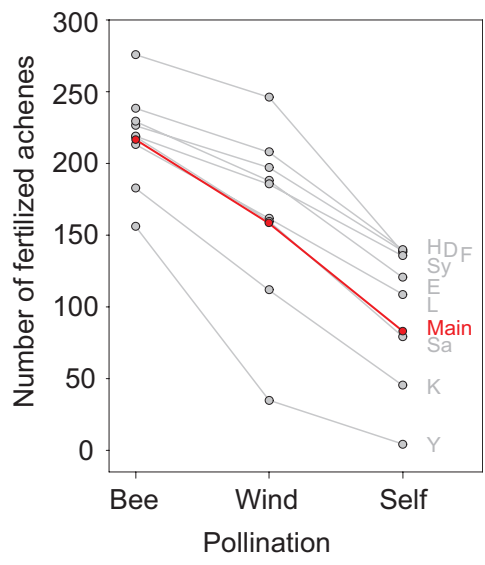

Fig. 4. Bee pollination had higher pollination success, calculated as the number of fertilized achenes per fruit. Further details and abbreviations are explained in the legend of Fig. 1. strawberries (Free 1993), but further highlights the importance of wild bees for crop pollination. The mechanism behind the benefits of bee pollination is based on the fertilization of the true "nut" fruits of the strawberry, the achenes (Given et al. 1988; Roussos et al. 2009; Villareal et al. 2009; Csukasi et al. 2011). During their visits, bees allocate pollen homogeneously on the receptacles, increasing the number of fertilized achenes per fruit (Svensson 1991). Unfertilized achenes resulting from insufficient pollination have no physiological functionality (Free 1993). Fertilized 
achenes produce the plant hormone auxin, which mediates the accumulation of gibberellic acids (Csukasi et al. 2011). Together, these plant hormones induce fruit growth by improving cell progeny and size and enhance the weight and quality of berries (Roussos et al. 2009). Enhanced levels of auxin and presumably gibberellic acid (Villareal et al. 2009) also delay fruit softening (enhance firmness and shelf life) by limiting the expression of several fruit-softening proteins, the so-called expansins (Given et al. 1988). Whereas auxin alone reduces the accumulation of anthocyanins (Given et al. 1988), it is increased by higher levels of both plant hormones together (Roussos et al. 2009). In contrast to firmness and colour changes, sugar-acid-ratios of strawberries are not directly affected by auxin and gibberellic acid (Roussos et al. 2009). But higher firmness of fruits based on persistent cell walls might reduce respiration, which is known to limit metabolic processes affecting sugar and acid contents during storage (Caner et al. 2008), so that indirect positive effects of pollination are probable.

CONCLUSIONS. In conclusion, our results showed that crop pollination is of higher economic importance than hitherto thought. Quality improvements of crops can greatly affect marketability and contribute to reducing crop waste. In the industrialized countries, $40 \%$ of all crops are thrown away at retail and consumer levels (Tscharntke et al. 2012; Gustavsson et al. 2011). Under the current scenario of rapid human population increase and global food demand (Godfray 2010), achieving high quality and quantity of crops is a pressing issue. Our study suggests that comprehensive analyses of the benefits of pollination for animal-dependent crops, which comprise $70 \%$ of all major crop species, may significantly increase 
estimates of the economic value of this ecosystem service. It is economically much more important than previously recognized and needs better implementation in agricultural management policies.

ACKNOWLEDGMENTS. We thank, K. M. Krewenka, J. Fründ, C. Scherber, M. von Fragstein, G. Everwand, B. Scheid, K. Klatt and H. P.-G. Klatt for comments on the manuscript and N. Blüthgen, D. Kleijn and L. Garibaldi for reviewing the manuscript prior to submission. We thank the members and technicians of the agroecology group for their field assistance. This work has been supported by the German Research Foundation (DFG; TS45/29-1).

\section{REFERENCES}

AMI - Agrarmarkt Informations-Gesellschaft mbH, 2012. (http://www.ami-informiert.de/ ami-english/ami-about-us.html).

Al-Attal, Y.Z., Kasrawi, M.A. \& Nazer, I.K. (2003) Influence of pollination technique on greenhouse tomato production. Journal of Agricultural \& Marine Sciences, 8, 21-26.

Ariza, M.T., Soria, C., Medina, J.J. \& Martinez-Ferri, E. (2010) Fruit misshapen in strawberry cultivars (Fragaria $x$ ananassa) is related to achenes functionality. Annals of Applied Biology, 158, 130-138.

Bolker, B.M., Brooks, M.E., Clark, C.J., Geange, S.W., Poulsen, J.R., Stevens, M.H.H. \& White, J.-S.S. (2009) Generalized linear mixed models: a practical 
guide for ecology and evolution. Trends in Ecology and Evolution, 24, $127-135$.

Burnham, K.P. \& Anderson, D.R. (2002) Model selection and multimodel inference: a practical information-theoretic approach. Springer Verlag, New York, NY, USA.

Caner, C., Aday, M.S. \& Demir, M. (2008), Extending the quality of fresh strawberries by equilibrium modified atmosphere packaging. European Food Research and Technology, 227, 1575-1583.

Choi, Y.H., Kang, N.J., Park, K.S., Chun, L., Cho, M.W., Um, Y.C. \& You, H.Y. (2009) Influence of fruiting methods on fruit characteristics in cherry tomato. Korean Journal of Horticultural Science \& Technology. 27, 62-66.

Civello, P.M., Martinez, G.A., Chaves, R.A. \& Anon, M.C. (1999) An expansin gene expressed in ripening strawberry fruit. Journal of Agricultural and Food Chemistry, 45, 4589-4594.

Colla, E., Sobral, P.J.A. \& Menegalli, F.C. (2006) Effect of composite edible coating from Amaranthus cruentus flour and stearic acid on refrigerated strawberry (Fragaria ananassa) quality. Latin American Applied Research, 36, 249-254.

Csukasi, F., Osorio, S., Gutierrez, J.R., Kitamura, J., Giavalisco, P., Nakajima, M., Fernie, A.R., Rathjen, J.P., Botella, M.A., Valpuesta, V. \& Medina-Escobar, N. (2011) Gibberellin biosynthesis and signalling during developement of the strawberry receptacle. New Phytologist, 191, 376-390.

Cuevas, J., Huesco, J.J. \& Puertas, M. (2003) Pollination requirements of loquat (Eriobotrya japonica Lindl.) cv. 'Algerie'. Fruits, 58, 157-167. 
Dag, A. \& Mizrahi, Y. (2005) Effect of pollination method on fruit set and fruit characteristics in the vine cactus Selenicereus megalanthus ("yellow pitaya"). The Journal of Horticultural Science and Biotechtology, 80, 618-622.

European commission (2007) Commission Regulation (EC) No 1580/2007. (http:// ec.europa.eu/index_en.htm).

FAOSTATS - Food and Agricultural Organaziation of the United Nations (2012). Statistical Devision. http://faostat.fao.org/default.aspx.

Free, J.B. (1993) Insect Pollination of Crops. Academic Press, London, UK.

Freihat, N.M., Al-Ghzawi, A.A.-M., Zaitoun, S. \& Alqudah, A. (2008) Fruit set and quality of loquats (Eriobotrya japonica) as effected by pollinations under subhumid Mediterranean. Scientia Horticulturae, 117, 58-62.

Gajc-Wolska, J., Kowalczyk, K., Mikas, J. \& Drajski, R. (2011) Efficiency of cucumber (Cucumis sativus L.) pollination by bumblebees (Bombus terrestris). Acta Scientiarum Polonorum, 10, 159-169.

Gallai, N., Salles, J.-M., Settele, J. \&Vaissiere, B.E. (2009) Economic valuation of the vulnerability of world agriculture confronted with world pollinator decline. Ecological Economics, 68, 810-821.

Given, N.K., Venis, M.A. \& Grierson, D. (1988) Hormonal regulation of ripening in the strawberry, a nonclimacteric fruit. Planta, 174, 402-406.

Godfray, H.C.J. (2010) Food security: the challenge of feeding 9 billion people. Science, 327, 812-818.

Gustavsson, J., Cederberg, C., Sonesson, U., van Otterdijk, R. \& Meybeck, A. (2011) Global food losses and food waste: extent, causes and prevention. FAO. 
Hernandez-Munoz, P., Almenar, E., Ocio, M.J. \& Gavara, R. (2006) Effect of calcium dips and chitosan coatings on postharvest life of strawberries (Fragaria x ananassa). Postharvest Biology and Technology, 39, 247-253.

Klein, A.-M., Vaissiere, B.E., Cane, J.H., Steffan-Dewenter, I., Cunningham S.A., Kremen, C. \& Tscharntke, T. (2007) Importance of pollinators in changing landscapes for world crops. Proceedings of the Royal Society B, 274, 303-313.

Potts, S.G., Biesmeijer J.C., Kremen, C., Neumann, P., Schweiger, O. \& Kunin, W.E. (2010) Global pollinator declines: trends, impacts and drivers. Trends in Ecology and Evolution, 25, 345-353.

Roussos, P.A., Denaxa, N.-K. \& Damvakaris, T. (2009) Strawberry fruit quality attributes after application of plant growth stimulating compounds. Scientia Horticulturae, 119, 138-146.

Sanz, C., Perez, A.G., Olias, R. \& Olias, J.M. (1999) Quality of strawberries packed with perforated polypropylene. Journal of Food Science, 64, 748-752.

Seeram, N.P. (2008) Berry fruits: compositional elements, biochemical activities, and the impact of their intake on human health, performance, and disease. Journal of Agricultural and Food Chemistry, 56, 627-629.

Shin, Y.S., Park, S.D. \& Kim, J.H. (2007) Influence of pollination methods on fruit development and sugar contents of oriental melon (Cucumis melo L. cv. Sagyejeol-Ggul). Scientia Horticulturae, 112, 88-392.

Svensson, B., (1991) The importance of honeybee-pollination for the quality and quantity of strawberries (Fragaria $x$ ananassa) in Central Schweden. Acta Horticulturae, 288, 260-264.

Tscharntke, T., Clough, Y., Wanger, T.C., Jackson, L., Motzke, I., Perfecto, I., Vandermeer, J. \& Whitbread, A. (2012) Global food security, biodiversity 
conservation and the future of agricultural intensification. Biological Conservation, 151, 53-59.

Villareal, N.M., Martinez, G.A. \& Civello, P.M. (2009) Influence of plant growth regu-lators on polygalacturonase expression in strawberry fruit. Plant Science, 176, 740-757. 


\section{SUPPLEMENTARY INFORMATION}
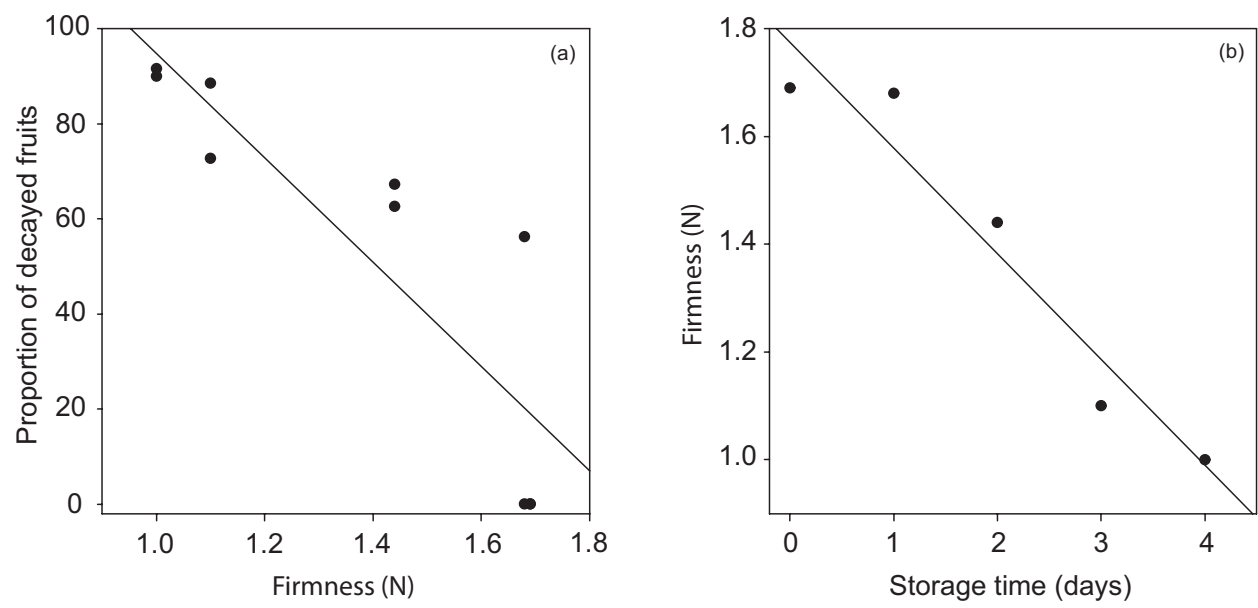

Fig. S1. Correlation between firmness and shelf life of strawberries based on published data (11). (a) The proportion of fruits lost due to fungal and surface decay correlated to firmness. At a firmness of $1.23 \mathrm{~N}, 50 \%$ of the fruits were lost due to surface and fungal decay (Spearman's correlation $=-0.87 ; P=0.001)$. (b) Firmness loss based on storage time. Firmness decreased about $0.2 \mathrm{~N}$ per day (Spearman's correlation $=-0.97 ; P=0.008$ ) at a temperature of $20^{\circ} \mathrm{C}$. 

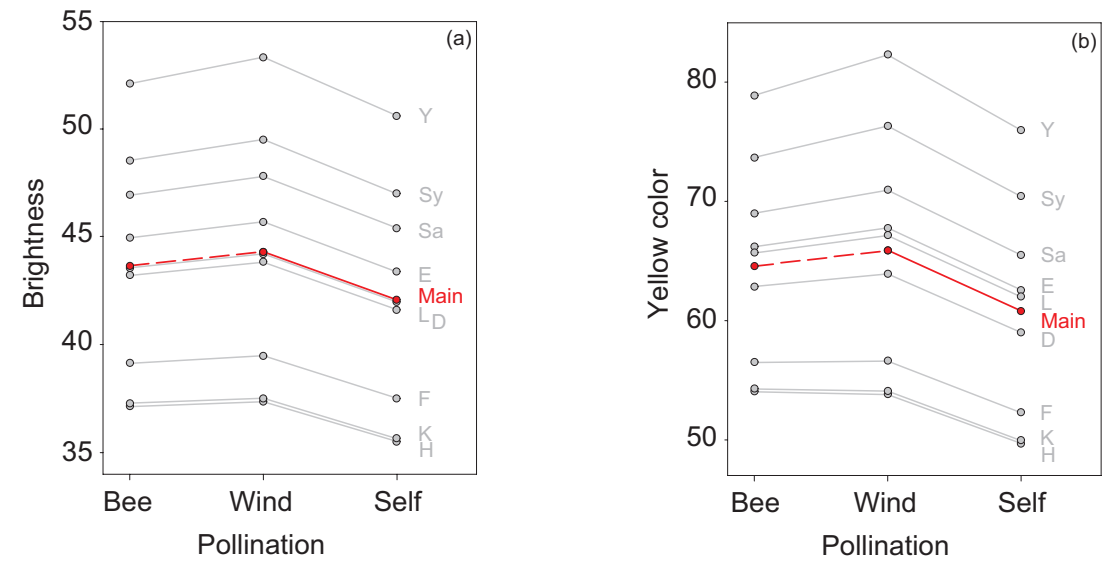

Fig. S2. Effects of pollination treatments on the yellow colour and brightness of strawberry varieties. (a) Brightness. (b) Yellow colour. Variety effects were stronger that differences between bee and wind pollination impe-ding a main effect (indicated by red lines for the main effect displayed dashed; see Table S2 for AICc and likeliness values). Further details and abbreviations are explained in the legend of Fig. 1. 
Table S1. Bee pollinators visiting strawberries on the experimental field. To identify the main pollinators of strawberry flowers on the experimental field, four varieties were randomly selected and insects pollinating strawberry flowers were collected. Sweep netting was conducted for ten minutes on four transects that were randomly selected on each of four different days in 2010. Strawberries were mainly pollinated by solitary wild bees with $O$. bicornis being the most frequent species, while honey bees (A. mellifera) and bumble bees (Bombus spp.) were less abundant.

Species

Abundance

Proportion

Osmia bicornis

114

38.9

Apis mellifera

Bombus terrestris

71

3.4

Andrena flavipes

2.7

Bombus lapidarius

1.7

Andrena sp.

1.4

Andrena gravida

0.7

Bombus pascuorum

0.7

Bombus pratorum

0.7

Andrena chrysosceles

0.3

Bombus hypnorum

0.3

Bombus sp. 
Table S2. Delta AICc values and likeliness resulting from model comparisons. $A I C c=0$ indicates the model with the highest explanatory power. Lower delta $\mathrm{AICc}$ and higher likeliness values indicate better explanatory power of a model. Likeness was calculated between models with delta AICc less than seven (Burnham \& Anderson 2002). Likeliness values are signed with asterisk. Best explaining models are highlighted in bold. None $=$ no level pooled; Sans $=$ model without fixed effect.

\begin{tabular}{|c|c|c|c|c|c|}
\hline \multirow[t]{2}{*}{ Fruit parameter } & \multicolumn{5}{|c|}{ Pooled levels } \\
\hline & None & Bee $=$ Wind & Wind $=$ Self & Bee $=$ Self & Sans \\
\hline \multirow[t]{2}{*}{ Commercial value } & 0 & 4.512 & 0.173 & 3.527 & 2.501 \\
\hline & ${ }^{*} 0.403$ & ${ }^{*} 0.042$ & ${ }^{*} 0.370$ & ${ }^{*} 0.069$ & ${ }^{*} 0.115$ \\
\hline \multirow[t]{2}{*}{ Fruit weight } & 0 & 4.162 & 3.507 & 4.872 & 3.137 \\
\hline & $* 0.627$ & ${ }^{*} 0.078$ & ${ }^{*} 0.109$ & ${ }^{*} 0.055$ & ${ }^{*} 0.131$ \\
\hline \multirow[t]{2}{*}{ Shelf life } & 0 & 0.347 & 1.791 & 7.218 & 5.273 \\
\hline & ${ }^{*} 0.431$ & ${ }^{*} 0.362$ & ${ }^{*} 0.174$ & - & ${ }^{*} 0.031$ \\
\hline \multirow[t]{2}{*}{ Red colour } & 1.428 & 1.608 & 0 & 2.021 & 0.323 \\
\hline & ${ }^{*} 0.155$ & ${ }^{*} 0.142$ & $* 0.317$ & ${ }^{*} 0.115$ & ${ }^{*} 0.270$ \\
\hline \multirow[t]{2}{*}{ Sugar-acid-ratio } & 2.128 & 3.244 & 0 & 1.247 & 1.147 \\
\hline & ${ }^{*} 0.131$ & ${ }^{*} 0.075$ & ${ }^{*} 0.378$ & ${ }^{*} 0.203$ & ${ }^{*} 0.213$ \\
\hline \multirow[t]{2}{*}{ Pollination success } & 0 & 4.267 & 9.192 & 8.704 & 7.290 \\
\hline & ${ }^{*} 0.894$ & ${ }^{*} 0.106$ & - & - & - \\
\hline \multirow[t]{2}{*}{ Brightness } & 0.723 & 0 & 11.821 & 7.067 & 9.862 \\
\hline & ${ }^{*} 0.411$ & ${ }^{*} 0.589$ & - & - & - \\
\hline \multirow[t]{2}{*}{ Yellow colour } & 0.438 & 0 & 11.648 & 9.405 & 10.614 \\
\hline & ${ }^{*} 0.445$ & $* 0.555$ & - & - & - \\
\hline
\end{tabular}


Table S3. Effects of pollination on commercial grades separated for varieties.

\begin{tabular}{|c|c|c|c|c|}
\hline \multirow[t]{2}{*}{ Variety } & \multirow[t]{2}{*}{ Pollination treatment } & \multicolumn{3}{|c|}{ Commercial grade } \\
\hline & & Extra/One (\%) & Two (\%) & Non-marketable (\%) \\
\hline \multirow[t]{3}{*}{ Darselect } & Bee & 56.2 & 26.0 & 16.4 \\
\hline & Wind & 40.8 & 35.2 & 23.9 \\
\hline & Self & 48.3 & 33.7 & 18.0 \\
\hline \multirow[t]{3}{*}{ Elsanta } & Bee & 49.1 & 31.6 & 19.3 \\
\hline & Wind & 31.8 & 50.0 & 18.2 \\
\hline & Self & 43.9 & 25.5 & 30.6 \\
\hline \multirow[t]{3}{*}{ Florence } & Bee & 34.8 & 47.0 & 18.2 \\
\hline & Wind & 26.0 & 46.0 & 28.0 \\
\hline & Self & 22.0 & 42.4 & 35.6 \\
\hline \multirow[t]{3}{*}{ Honeoye } & Bee & 60.4 & 18.7 & 20.9 \\
\hline & Wind & 37.2 & 38.5 & 24.4 \\
\hline & Self & 30.1 & 35.3 & 34.6 \\
\hline \multirow[t]{3}{*}{ Korona } & Bee & 45.3 & 26.7 & 27.9 \\
\hline & Wind & 37.7 & 31.9 & 30.4 \\
\hline & Self & 29.4 & 25.2 & 45.4 \\
\hline \multirow[t]{3}{*}{ Lambada } & Bee & 43.3 & 16.4 & 40.3 \\
\hline & Wind & 23.6 & 32.7 & 43.6 \\
\hline & Self & 28.6 & 42.9 & 28.6 \\
\hline \multirow[t]{3}{*}{ Salsa } & Bee & 30.6 & 45.2 & 24.2 \\
\hline & Wind & 19.6 & 45.7 & 34.8 \\
\hline & Self & 1.9 & 55.6 & 42.6 \\
\hline \multirow[t]{3}{*}{ Symphony } & Bee & 48.3 & 27.6 & 24.1 \\
\hline & Wind & 45.3 & 22.6 & 32.1 \\
\hline & Self & 50.8 & 33.9 & 15.3 \\
\hline \multirow[t]{3}{*}{ Yamaska } & Bee & 60.3 & 19.0 & 20.6 \\
\hline & Wind & 8.0 & 32.0 & 60.0 \\
\hline & Self & 0.0 & 5.6 & 94.4 \\
\hline
\end{tabular}


Chapter 3

Enhancing crop shelf life with bee pollination

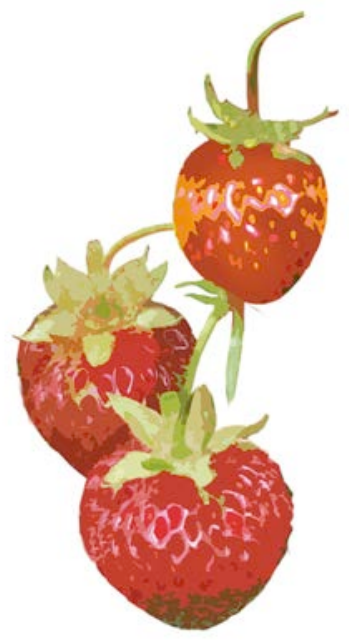




\section{SUMMARY}

1. Shelf life of crops is one of the most important quality parameters. It is influenced by pollination, but effects have not been quantified so far.

2. Commercial grades of strawberries are a function of pollination. We tested how firmness, fruit weight and decay changed in consiquence of commercial grades (determined by bee vs. wind pollination).

3. During storage time, firmness and fruit weight declined and the proportion of decayed fruits increased in all three commercial grades.

4. Fruits of higher commercial grades had higher firmness and weight as well as less decay, which resulted in smaller quality loss with storage time. After three days, half of the wind-pollinated fruits (lower grades), but only a fifth of the bee pollinated fruits (grade one) were decayed.

5. Synthesis and Applications. Crop pollination does not only increase yield, but also the economically most important shelf life. Hence, crop pollination has the potential to reduce food waste and pollinator conservation should be considered more seriously in international conservation strategies.

KEY-WORDS: commercial grade, crop quality, decay, degradation, firmness, food demand, quality, storage, strawberry, weight 
INTRODUCTION. A rising world population during the next decades will lead to increasing demands of food (Godfray et al. 2010). While increasing importance of pollination dependent crops highlight the need to stabilize pollination services (Aizen et al. 2008; Lautenbach et al. 2012), pollinators are endangered by various anthropogenic threats (Potts et al. 2010). There is some evidence that pollination can improve the quality of agricultural products such as fruits (Al-Attal, Kasrawi \& Nazer 2003; Cuevas, Hueso \& Puertas 2003; Dag \& Mizrahi 2005; Shin, Park \& Kim 2007; Freihat et al. 2008; Choi et al. 2009; Gajc-Wolska et al. 2011). Food quality has become a major topic with increasing attention in public, policies and science, last not least because high amounts of food are wasted worldwide due to insufficient quality (Gustavsson et al. 2011; Tscharntke et al. 2012)

Fruits are the most pollination dependent agricultural products (Klein et al. 2007). An important economic factor determining the quality of fruits is their shelf life (Manning 1998). The quality of fruits is declining during storage, due to fruit softening, which leads to weight loss and decay (Toivonem \& Brummel 2008). Thus the shelf life of fruits is mainly dependent on fruit softening, represented by the firmness of fruits (Toivonem \& Brummel 2008).

So far only four publications reported that the firmness of fruits can be enhanced by insect pollination (Al-Attal et al. 2003; Shin et al. 2007; Gajc-Wolska et al. 2011). The importance of strawberries is increasing worldwide (FAOSTATS 2012) and strawberry yield has been shown to strongly benefit from pollination. Strawberry pollination is mainly conducted by bees and leads to fruits with less malformations and higher weight (Free 1993; Zebrowska 1998). However, a direct relationship between shelf life and pollination for strawberries or any other crop has not been shown so far. 
The aim of this study was to analyze the relationship between pollination and shelf life of fruits, using strawberry as a study organism. Strawberries were classified into commercial grades based on malformations mediated by insufficent pollination. Bee pollinated fruits have a higher amount of fertilized achenes than wind pollinated fruits, showing the effectivity of pollination conducted by bees. Firmness, fruit weight and decay as parameters determining shelf life were measured during storage. We expect those fruits pollinated by bees and of higher commercial grades to have higher amounts of fertilized achenes. Fruit quality during storage should decline due to decreasing firmness and fruit weight and increasing proportions of decayed fruits. This degradation will vary in dependence on commercial grades.

MATERIAL \& METHODS. In 2009, exclusion treatments considering bee, wind and self pollination were conducted on an experimental strawberry field with nine strawberry varieties (Fragaria $\mathrm{x}$ ananassa Duch.; Chapter 2). From this experiment, bee and wind pollinated fruits of the variety Yamaska, that were sorted into commercial grades based on malformations resulting from insufficient pollination, were used for the current study. Thus commercial grades signed pollination success representing different levels of pollination. The variety Yamaska does not produce antheres, so it depends on cross pollination.

Fruits were collected at maturity, when more than $75 \%$ of the surface were coloured red and divided into commercial grades following the Regulation of the European Community (2007). Fruits were blended separately in $100 \mathrm{ml}$ distilled water for two minutes (Speedy Pro GVA 1, Krups, Offenbach, Germany). Fertilized achenes are heavier than water and sink to the bottom whereas aborted achenes are lighter and 
accumulate at the water surface. Fertilized achenes were counted (Contador, Pfeuffer, Kitzingen Germany) after drying for 48 hours at $85^{\circ} \mathrm{C}$.

In 2012 fruits of the same variety from a conventionally managed strawberry field near the city of Goettingen, Germany, were used. As for 2009, fruits were collected at maturity and classified into three commercial grades based on malformations resulting from insufficient pollination. All selected fruits did not show any physical damage or fungal infection.

To simulate retail conditions, fruits were stored at $20{ }^{\circ} \mathrm{C}$ (Sanz et al. 1999; Colla, Sobral \& Menegalli 2006; Hernandez-Munoz et al. 2006) for four days. Dependent on their availability on the field, a random set of 7 to 13 fruits from each commercial

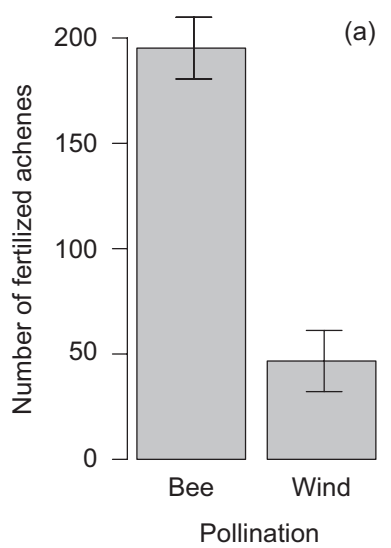

(a)

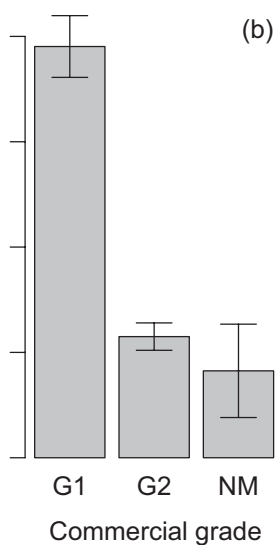

Fig. 1. Differences in the mean number of fertilized achenes for pollination treatments and commercial grades. (a) Mean number of achenes for pollination treatments resulting from exclusion experiments. (b) Mean number of achenes for commercial grades. The mean number of fertilized achenes significantly differed between pollination treatments $\left(\Delta\right.$ Deviance $_{(1,9)}=14.10 ; P<$ $0.001)$ and commmercial grades $\left(\Delta\right.$ Deviance $_{(2,8)}=15.03 ; P<$ 0.001 ), respectively. $\mathrm{G} 1=$ grade one, $\mathrm{G} 2$ = grade two, NM = nonmarketable. $P<0.05=$ significant. grade was used for analysis on each consecutive day. Fruits were weighted (BA2001 S, Sartorius, Goettingen, Germany) and visually inspected for physical and fungal decay.

For firmness analysis, the peduncle and calyx were removed and fruits were bisected. Firmness was measured at the center of each half according to Sanz et al. (1999), using a texture analyser (TAXT2 Textur Analyzer, Stable Micro Systems, Surrey, UK) 
fitted with a $5 \mathrm{~mm}$ diameter probe and a $25 \mathrm{~kg}$ compression cell with the following adjustments: pre-test speed $6.00 \mathrm{~mm} / \mathrm{sec}$; t test speed $1.0 \mathrm{~mm} / \mathrm{sec}$; post-test speed 8.0 $\mathrm{mm} / \mathrm{sec}$; penetration distance $4 \mathrm{~mm}$; trigger force $1.0 \mathrm{~N}$. The maximum force in Newton reached during tissue breakage was recorded as firmness and mean values of both halves for each fruit were used for statistical analysis.

Generalized linear models (package "MASS“; Venables \& Ripley 2002) with negative binomial distribution were fitted in $R$ ( $R$ Development Core Team 2012) to analyse the relationship between pollination treatments as well as commercial grades and the number of fertilized achenes.

Linear models (package "stats"; R Development Core Team 2012) were used to test effects of storage time in interaction with commercial grades on fruit weight and firmness, respectively.

Generalized linear models (package "base"; Venables \& Ripley 2002) with quasibinomial distribution were fitted to test whether storage time and commercial grades had an effect on the proportion fruit decay.

Residuals were inspected to meet model assumptions. $P$-values were defined as significant if smaller than 0.05 .

RESULTS. Bee pollinated strawberry fruits had a significantly higher number of fertilized achenes than wind pollinated fruits $\left(\Delta\right.$ Deviance $_{1,9}=14.10 ; P<0.001$; Fig. 1). Calculating the number of achenes between commercial grades showed that fruits of grade one had a much higher number of fertilized achenes compared to fruits of grade two and non-marketable fruits $\left(\Delta\right.$ Deviance $_{2,8}=15.03 ; P<0.001$; Fig. 1). Bee pollination exclusively resulted in fruits of grade one, while all wind 
pollinated fruits were of the minor grade two or even non-marketable (Fig. 1). Firmness $\left(F_{1,151}=96.597 ; P<0.001 ;\right.$ Fig. $\left.2 \mathrm{a}\right)$ and fruit weight $\left(F_{1,154}=41.836 ; P<\right.$ 0.001; Fig. 2b) significantly declined during storage time, while the proportion of decayed fruit was increasing $\left(F_{1,155}=151.110 ; P<0.001\right.$; Fig. $\left.2 \mathrm{c}\right)$. Declines in
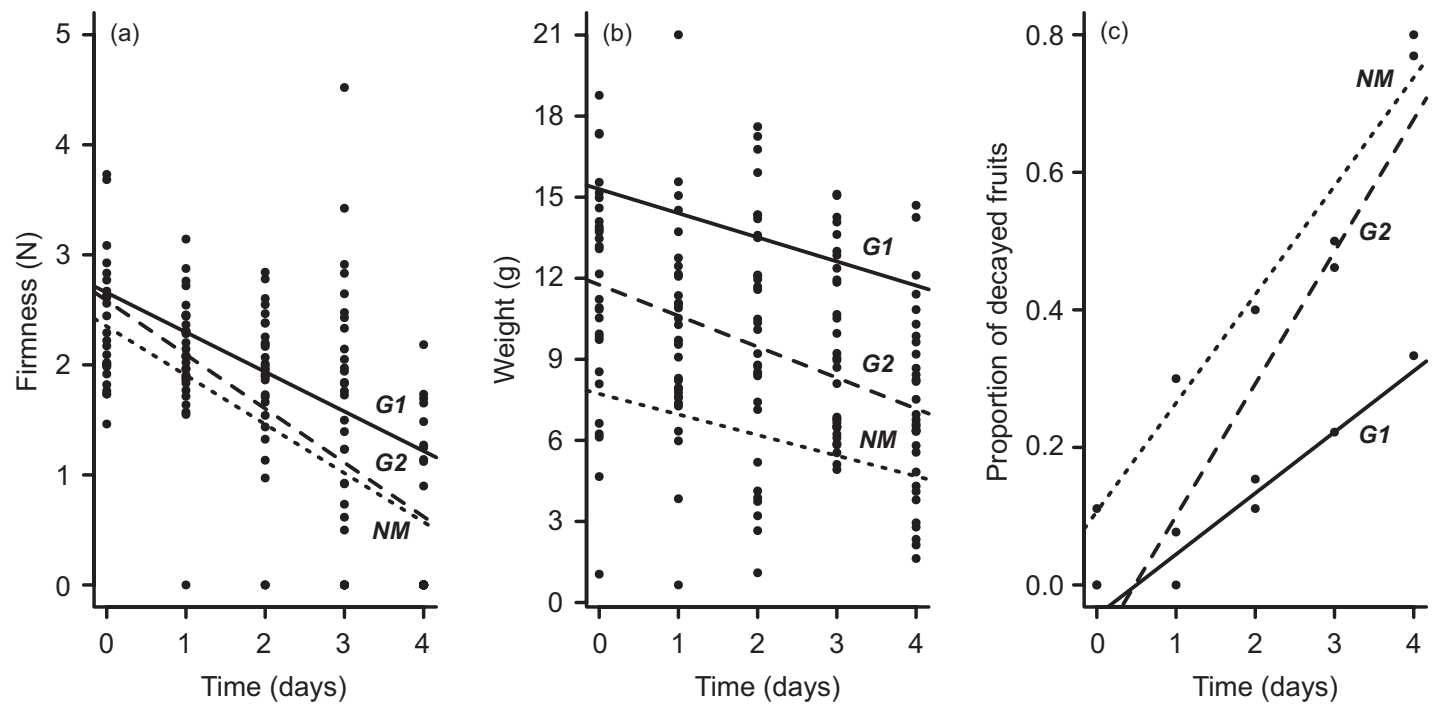

Fig. 2. Fruit degradation during storage in dependence on commercial grades. (a) Firmness. (b) Fruit weight. (c) Proportion of decayed fruits. Firmness $\left(F_{1,151}=96.597 ; P<0.001\right)$ and fruit weight $\left.F_{1,154}=41.836 ; P<0.001\right)$ significantly decreased during storage time, while fruit decay increased $\left(F_{1,155}=151.110 ; P<0.001\right)$, with no difference between commercial grades. Commercial grades generally differed for each parameter (firmness: $F_{1,151}=$ 8.214; $P=0.005$; fruit weight: $F_{1,154}=184.896 ; P<0.001$; fruit decay: $F_{1,154}=14.501 ; P<0.001$ ). Solid lines show grade one, dashed lines show grade two, pointed lines show non-marketable fruits. $G 1=$ grade one, $G 2=$ grade two, NM = non-marketable. $P<0.05=$ significant.

firmness and fruit weight and the increase in fruit decay did not differ in slope between commercial grades. However, commercial grades mattered. Better commercial grades showed higher values of firmness $\left(F_{1,151}=8.214 ; P=0.005\right.$; Fig. 2a) and fruit weight $\left(F_{1,154}=184.896 ; P<0.001\right.$; Fig. $\left.2 \mathrm{~b}\right)$ as well as lower 
proprortions of decayed fruits $\left(F_{1,154}=14.501 ; P<0.001\right.$; Fig. $\left.2 \mathrm{c}\right)$ during the entire storage time.

Fruit decay was negatively correlated to firmness (Pearson's correlation $=-0.93 ; P$ $<0.001$ ) and fruit weight (Pearson's correlation $=-0.73 ; \mathrm{P}=0.002$ ), while firmness and fruit weight were less, but positively correlated (Pearson's correlation $=0.65 ; \mathrm{P}$ $=0.009)$.

DISCUSSION. Our results demonstrate a relationship between pollination, commercial grades and the shelf life of strawberries. Bee pollinated fruits had a higher number of fertilized achenes and were of higher commercial grades than fruits resulting from wind pollination. Firmness and fruit weight of strawberries decreased during storage time, while the proportion of decayed fruits was increasing. The shelf life of strawberries is short, based on fast quality losses during storage, which is due to their high metabolic activity and sensitivity to fungal decay (Hernandez-Munoz et al. 2006). During fruit ripening, cell wall degrading proteins, so called expansins (Given, Venis \& Grierson 1988) are produced, which lead to decreasing firmness and increasing decay during storage (Hernandez-Munoz et al. 2006), reducing firmness, due to the degradation of cell walls, higher respiration rates and the loss of water (Hernandez-Munoz et al. 2006). Thereby strawberry fruits become softer and often muddy as well as more sensitive to fungal decay (Hernandez-Munoz et al. 2006), resulting in fruit decay being correlated to firmness and fruit weight in our results.

Although commercial grades had similar rates of degradation, fruits with higher commercial grades, resulting from successful bee pollination, had a longer shelf life 
due to improved values. Bee pollination leads to a higher number of fertilized achenes (Free 1993; Zebrowska 1998), which produce the hormonal growth factor auxin (Nitsch 1950; Csukasi et al. 2011) that in turn mediates the production of another growth factor, gibberellic acid (Csukasi et al. 2011). Both enhance cell progeny and size and thus fruit weight (Roussos, Denaxa \& Damvakaris 2009) and improve firmness by limiting the production of expansins (Villareal, Martinez \& Civello 2009). This further prevents malformations, which are caused by areas of unfertilized and thus physiologically inactive achenes (Nitsch 1950; Ariza et al. 2010), thus improving commercial grades.

CONCLUSIONS. In conclusion, pollination appears to be a key factor for the shelf life of strawberries. We showed for the first time, that bee pollination essentially elongated the shelf life of crops, which is based on growth factors that are known for many important crops (Toivonem \& Brummel 2008). After three days, half of the wind pollinated strawberry fruits, but only a fifth of the bee pollinated fruits were decayed. Pollination contributes to more than one third of the global crop production and has been mainly related to just fruit set, fruit weight and overall yield (Klein et al. 2007). Increased shelf life due to crop pollination also results in less food waste due to insufficient quality (Gustavsson et al. 2011; Tscharntke et al. 2012). Our results provide a new perspective on the dependence of food shelf life on pollination, emphasizing the need to protect and enhance pollination services in international conservation strategies. 
ACKNOWLEDGEMENTS. The authors thank K. Mecke for the permission to collect strawberry fruits at his field as well as I. Smit and E. Pawelzik for the provision with lab space and instruments. We thank U. Kierbaum for essential assistance during fieldwork and M. von Fragstein for discussion and comments on earlier drafts of this manuscript. This work has been fundet by the German Research Foundation (DFG; TS 45/29-1).

\section{REFERENCES}

Aizen, M.A., Garibaldi, L.A., Cunningham, S.A. \& Klein, A.-M. (2008) Long-term global trends in crop yield and production reveal no current pollination shortage but increasing pollinator dependency. Current Biology, 18, 15721575 .

Al-Attal, Y.Z., Kasrawi, M.A. \& Nazer, I.K. (2003) Influence of pollination technique on greenhouse tomato production. Journal of Agricultural and Marine Sciences, 8, 21-26.

Ariza, M.T., Soria1, C., Medina, J.J. \& Martinez-Ferri, E. (2010) Fruit misshapen in strawberry cultivars (Fragaria $x$ ananassa) is related to achenes functionality. Annals of Applied Biology, 158, 130-138.

Choi, Y.H., Kang, N.J., Park, K.S., Chun, L., Cho, M.W., Um, Y.C. \& You, H.Y. (2009) Influence of fruiting methods on fruit characteristics in cherry tomato. Korean Journal of Horticultural Science \& Technology, 27, 62-66.

Colla, E., Sobral, P.J.A. \& Menegalli, F.C. (2006) Effect of composite edible coating from Amaranthus cruentus flour and stearic acid on refrigerated strawberry (Fragaria ananassa) quality. Latin American Applied Research, 36, 249-254. 
Cuevas, J., Hueso, J.J. \& Puertas, M. (2003) Pollination requirements of loquat (Eriobotrya japonica Lindl.), cv. 'Algerie'. Fruits, 58, 157-165.

Csukasi, F., Osorio, S., Gutierrez, J.R., Kitamura, J., Giavalisco, P., Nakajima, M., Fernie, A.R., Rathjen, J.P., Botella, M.A., Valpuesta, V. \& Medina-Escobar, N. (2011) Gibbellerin biosynthesis and signalling during developement of the strawberry receptacle. New Phytologist, 191, 376-390.

Dag, A. \& Mizrahi, Y (2005) Effect of pollination method on fruit set and fruit characteristics in the vine cactus Selenicereus megalanthus ("yellow pitaya"). The Journal of Horticultural Science and Biotechnology, 80, 618-622.

European commission (2007) Commission Regulation (EC) No 1580/2007. (http:// ec.europa.eu/index_en.htm).

FAOSTATS - Food and Agricultural Organization of the United Nations (2012). Statistical Devision. http://faostat.fao.org/default.aspx.

Free, J.B. (1993) Insect Pollination of Crops. Academic Press, London, UK.

Freihat, N.M., Al-Ghzawi, A.A.-M., Zaitoun, S. \& Alqudah, A. (2008) Fruit set and quality of loquats (Eriobotrya japonica) as effected by pollinations under subhumid Mediterranean Scientia Horticulturae, 117, 58-62.

Gajc-Wolska, J., Kowalczyk, K., Mikas, J., Drajski, R. (2011) Efficiency of cucumber (Cucumis sativus L.) pollination by bumblebees (Bombus terrestris) Acta Scientiarum Polonorum, 10, 159-169.

Given, N.K., Venis, M.A. \& Grierson, D. (1988) Hormonal regulation of ripening in the strawberry, a nonclimacteric fruit. Planta, 174, 402-406.

Godfray, H.J.C. (2010) Food security: the challenge of feeding 9 billion people. Science, 327, 812-818. 
Gustavsson, J., Cederberg, C., Sonesson, U., van Otterdijk, R. \& Meybeck A. (2011) Global food losses and food waste: extent, causes and prevention. FAO, Rome, Italy.

Hernandez-Munoz, P., Almenar, E., Ocio, M.J. \& Gavara, R. (2006) Effect of calcium dips and chitosan coatings on postharvest life of strawberries (Fragaria x ananassa). Postharvest Biology and Technology, 39, 247-253.

Klein, A.-M., Vaissiere, B.E., Cane, J.H., Steffan-Dewenter, I., Cunningham S.A., Kremen, C. \& Tscharntke, T. (2007) Importance of pollinators in changing landscapes for world crops. Proceedings of the Royal Society B, 274, 303-313.

Lautenbach, S., Seppelt, R., Liebscher, J. \& Dormann, C.F. (2012) Spatial and temporal trends of global pollination benefit. PLoS ONE, 7, e35954.

Nitsch, J.P. (1950) Growth and morphogenesis of the strawberry as related to auxin. American Journal of Botany, 37, 211-215.

Manning, K. (1998) Genes for fruit quality in strawberry. Cab international, Wallingford, UK.

Potts, S.G., Biesmeijer J.C., Kremen, C., Neumann, P., Schweiger, O. \& Kunin, W.E. (2010) Global pollinator declines: trends, impacts and drivers. Trends in Ecology and Evolution, 25, 345-353.

R Development Core Team (2011) R: A language and environment for statistical computing. $R$ foundation for statistical computing. http://www.R-project.org.

Roussos, P.A., Denaxa, N.-K. \& Damvakaris, T. (2009) Strawberry fruit quality attributes after application of plant growth stimulating compounds. Scientia Horticulturae, 119, 138-146. 
Sanz, C., Perez, A.G., Olias, R. \& Olias, J.M. (1999) Quality of strawberries packed with perforated polypropylene. Journal of Food Science, 64, 748-752.

Shin, Y.S., Park, S.D. \& Kim, J.H. (2007) Influence of pollination methods on fruit development and sugar contents of oriental melon (Cucumis melo L. cv. Sagyejeol-Ggul) Scientia Horticulturae, 112, 88-392.

Toivonem, P.M.A \& Brummel, D.A. (2008) Biochemical bases of appearance and texture changes in fresh-cut fruit and vegetables. Postharvest Biology and Technology, 48, 1-14.

Tscharntke, T., Clough, Y., Wanger, T.C., Jackson, L., Motzke, I., Perfecto, I., Vandermeer, J. \& Whitbread, A. (2012) Global food security, biodiversity conservation and the future of agricultural intensification. Biological Conservation, 151, 53-59.

Venables, W.N. \& Ripley, B.D. (2002) Modern applied statistics with S. Springer, New York, NY, USA.

Villareal, N.M., Martinez, G.A. \& Civello, P.M. (2009) Influence of plant growth regulators on polygalacturonase expression in strawberry fruit. Plant Science, 176, 740-757.

Zebrowska, J. (1998) Influence of pollination modes on yield components in strawberry (Fragaria x ananassa Duch.). Plant Breeding, 117, 255-260. 
Chapter 4

Flower volatiles of crop varieties and bee responses

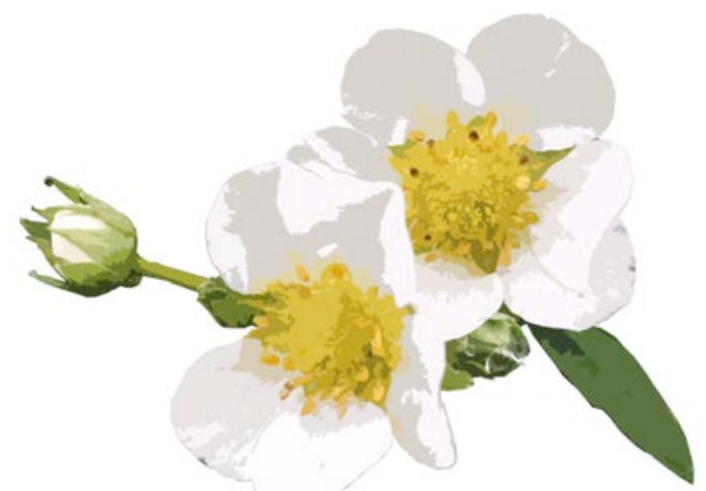




\section{SUMMARY}

1. Pollination affects a third of global food production, improving both yield and quality of crops. Volatile compounds of crop flowers mediate plantpollinator interactions, but differences between crop varieties are still little explored.

2. We investigated whether crop flower visitation is determined by varietyspecific flower volatiles using strawberry varieties (Fragaria $x$ ananassa Duch.) and the pollination services of the wild bee Osmia bicornis L..

3. Flower volatile compounds of three strawberry varieties were measured via headspace collection. Gas chromatographic analysis showed that the three strawberry varieties produced the same volatile compounds but with quantitative differences.

4. Electroantennographic recordings showed that inexperienced females of $O$. bicornis had higher antennal responses to all volatile compounds than to controls of air and paraffin oil, while responses differed between compounds. The variety Sonata, which emitted more of the compounds that evoked highest antennal responses than the variety Honeoye, received also more flower visits of $O$. bicornis females under field conditions.

5. Our results suggest that differences in the emission of flower volatile compounds between strawberry varieties mediate their attractiveness to females of $O$. bicornis. Since quantity and quality of marketable fruits depend on optimal pollination, the role of flower volatiles in crop production need to be better understood and more considered in crop-variety breeding. 
KEY-WORDS: abundance, antennal responses, bee visitation rates, flower volatile composition, Osmia bicornis, pollinator attraction, scent, wild bees, volatile mediated differences 
INTRODUCTION. Globally increasing food demand due to a rapidly rising world population (Godfray et al. 2010) highlights the importance of world food security (Lautenbach et al. 2012). Contributing to more than one third of world crop yield (Klein et al. 2007), pollination appears to be key factor to sustain the stability of agricultural food production (Tscharntke et al. 2012). However, our knowledge of crop pollination is still limited (Mayer et al. 2011). Recent threats on pollination services (Potts et al. 2010), due to declining populations of honeybees (Anderson et al. 2008) and wild bees (Biesmeijer et al. 2006), emphasize to expand the knowledge about bee-flower interactions to maintain pollination services (Dötterl \& Vereecken 2010).

The influence of floral traits such as colour, shape and handiness on the foraging behaviour of bees has been widely analysed (Parachnowitsch \& Kessler 2010). But it has recently been shown that the scent of flowers can be of higher importance than for example flower size and colour (Parachnowitsch, Raguso \& Kessler 2012). Flower volatile compounds are further assumed to be the main drivers for visitation decisions of pollinators including flower constancy (Raguso 2008; Wright \& Schiestl 2009; Dötterl \& Vereecken 2010), but have so far mainly been reported for honeybees, bumble bees (Wright \& Schiestl 2009) and few spezialised wild bee species (Dötterl \& Vereecken 2010). However, the foraging behaviour of the red mason bee $O$. bicornis has recently been shown to be highly influnced by floral scents (Howell \& Alarcon 2007), but details about potentially compounds were missing. Thus pollination ecology is still scarcly linked to chemical traits (Kessler \& Halitschke 2009; Dötterl \& Vereecken 2010) and in particular our knowledge how crop varieties attract pollinators remains scarce (Rodriguez-Saona et al. 2011; Adler \& Irwin 2012). 
The concentration of floral volatile compounds can vary due to genetic differences as shown for subspecies (Chess, Raguso \& LeBuhn 2008) and populations at different locations (Dötterl, Wolf \& Jürgens 2005). Only few studies have so far reported differences between crop varieties (Beker et al. 1989; Robertson et al. 1993; Wright, Skinner \& Smith 2002; Pham-Delegue et al. 1989; Cheong et al. 2011; Rodriguez-Saona et al. 2011; Soler et al. 2011). Only four of these studies investigated the influence of varieties differing in volatile emissions on pollinator attraction (Beker et al. 1989; Pham-Delegue et al. 1989; Wright et al. 2002; Rodriguez-Saona et al. 2011).

In the current study we aim to highlight the importance of volatile emissions for the attractivity of crop varieties to wild bee pollinators and thus pollination efficiency. We analyse three strawberry varieties for differences on flower volatile emission and the influences on antennal responses as well visitation rates of the solitary wild bee $O$. bicornis. Due to the high abundance and efficient pollination services, $O$. bicornis has recently been classified as important for crop pollination services (Holzschuh, Dudenhöffer \& Tscharntke 2012; Jauker et al. 2012). Osmia bees have also been shown to be a suitable pollinator for strawberries (Chagnon, Gingras \& Oliveira 1993). Strawberries benefit from pollination by enhanced fruit shape and weight (Free 1993; Zebrowska 1998). Recent findings about pollination improving the marketability and postharvest quality of several strawberry varieties including shelf life (Chapters 2 and 3) highlight the overall importance of strawberry pollination. Strawberry breeding focuses on several plant parameters differing between varieties (CPVO 2012), but the attraction to pollinators appears to be neglected. The emission of volatile composition and quantities has so far been tested for a single variety (Hamilton-Kemp, Loughrin \& Anderson 1990) and female and 
hermaphroditic flowers are known to differ in their emission of volatiles (Ashman et al. 2005). Neither information about the influence of volatile compounds of strawberry flowers on pollinators, nor differences between varieties are known. In detail we analysed (i) the emission of flower volatile compounds comparing three simultaneously flowering strawberry varieties. (ii) The antennal response of females of $O$. bicornis to these compounds were measured and related to (iii) differences in the visition frequency of $O$. bicornis females on a commercial strawberry field. We expected strawberry varieties to differ in the qualitative and quantitative emission of flower volatile compounds. Antennal responses of $O$. bicornis females would differ between compounds. This would further mediate the visitation rates of $O$. bicornis females between strawberry varieties under field conditions.

MATERIAL \& METHODS. As scents can be highly variable depending on environmental conditions (Reinhard \& Srinivisan 2009), refrigerated strawberry plants were planted and grown separately in 10 liter vessels in an isolated greenhouse under standardised conditions $\left(20^{\circ} \mathrm{C}\right.$; $60 \% \mathrm{RH} ; 12 \mathrm{~h}$ daylight per $\left.24 \mathrm{~h}\right)$. Volatiles were sampled simultaneously on all plants. Varieties differed in the amount of open flowers, but produced similar flower overall mass $\left(F_{2,19}=0.839 ; P=\right.$ 0.448).

Volatiles were sampled on a charcoal trap (CLSA-Filter, Daumazan sur Arize, France) using a modified push-pull headspace collection system (Tholl et al. 2006) directly from flowers. The flowers were enclosed in a plastic roasting bag (Melitta $\mathrm{GmbH}$, Minden, Germany). Air was circulated through the trap by a miniature pump (Fürgut, Aichstetten, Germany) at a flow of $0.81 \mathrm{~min}^{-1}$. The sampling time was 2 
hours. Adsorbed volatiles were eluted with $50 \mu$ of dichloromethane/methanol (2:1). The solvents used were of analytical quality (Suprasolv quality, Merck/VWR, Darmstadt, Germany). After elution, samples were stored in an ultralow temperature freezer at $-80^{\circ} \mathrm{C}$.

Volatile samples were analysed with a coupled GC-MS consisting of a gas chromatograph Agilent type 6890 connected to a type 5973 quadrupole mass spectrometer (both Palo Alto, USA) with electron ionisation (EI, $70 \mathrm{eV}$ ). Two column types in a similar setup, a HP-5ms (Agilent, $30 \mathrm{~m}, 0.25 \mathrm{~mm}$ ID, and $0.25 \mu \mathrm{m}$ film thickness, phenylmethylsiloxane), and a HP-INNOWax (Agilent, $30 \mathrm{~m}, 0.25$ $\mathrm{mm}$ ID, and $0.25 \mu \mathrm{m}$ film thickness, polyethylenglycol), were used to analyse the composition of the extracts. An aliquot of $1 \mu 1$ was injected into the injector held at $250^{\circ} \mathrm{C}$. The oven temperature program was $50^{\circ} \mathrm{C}$ held for $1.5 \mathrm{~min}$, followed by an increase of $7.50{ }^{\circ} \mathrm{C} / \mathrm{min}$ to $200^{\circ} \mathrm{C}$, remaining at $200^{\circ} \mathrm{C}$ for $5 \mathrm{~min}$. Helium (purity $99.999 \%)$ was used as carrier gas $(1 \mathrm{ml} / \mathrm{min})$.

For identification of the constituents, mass spectra GC retention values and linear retention indices (Van den Dool \& Kratz 1963) were compared to those of authentic standards and those of the mass spectral databases and published parameters (Table 1). Databases used, were Wiley 9 combined with NIST '08 (McLafferty 2009) and "Terpenoids and Related Constituents of Essential Oils", a database available from MassFinder 3.07 software (Hochmuth Scientific Consulting, Hamburg, Germany).

Experiments were conducted with antenna of $O$. bicornis females using an EAG setup as described in Weissbecker, Holighaus \& Schütz (2004). The tests were carried out by manually injecting the synthetic volatile standards upstream the dissected antenna into a stream with synthetic air. To guarantee standard conditions 
stimuli were supplied every $120 \mathrm{~s} \cdot 10^{-3}(\mathrm{w} / \mathrm{w})$ dilutions of synthetic standards were prepared of benzaldehyde, 6-methyl-5-hepten-2-one, (Z)-3-hexenyl acetate, d/1limonene, nonanal, methyl salicylate, p-anidehyde, dihydro- $\beta$-ionone, geranyl acetne, $\beta$-ionone, and $(E, E)$ - $\alpha$-farnesene, in paraffin oil (Uvasol ${ }^{\circledR}$, spectrosc. qual., high visc., Merck, Darmstadt, Germany). Approximately $100 \mu$ of standard dilution or paraffin oil as a control were dropped on $2 \mathrm{~cm}^{2}$ filter paper pieces (Schleicher \& Schuell, Dassel, Germany). A soaked filter paper was inserted into a $10 \mathrm{ml}$ glass syringe (Poulten \& Graf GmbH, Wertheim, Germany). A typical stimulus was supplied by puffing $5 \mathrm{ml}$ of air over the antenna and repeated once for each compoud and control. The EAG response for each compound and control was recorded for $O$. bicornis.

The abundance of females of $O$. bicornis on the varieties Sonata and Honeoye was assessed using standardised transect walks on a commercial strawberry field. For each strawberry variety, two adjacent rows were subdivided into nine transects and females of $O$. bicornis, the most abundant wild bee, was counted while visiting strawberry flowers at morning and afternoon on 17 days (26 transect walks) at the variety Sonata and on 16 days (22 transect walks) at the variety Honeoye.

Statistical analyses were carried out using the software R, Version 2.13.2 (R Development Core Team, 2011). To test the differences of floral volatiles of the three cultivars we fitted generalized linear models ("glm"-function in package "stats and MASS"; Venables \& Ripley 2002) using quasipoisson distribution with cultivar as fixed factor. Multiple comparisons among varieties were calculated using Tukey contrasts with $P$-values adjusted by single-step method (“multcomp"-package; Hsu 1996). 
To calculate differences of EAG responses of $O$. bicornis females between synthetic compounds and paraffin oil and air control we fitted glm using quasipoisson distribution considered significant at $P<0.05$ (glm, $F$-test).

To test abundance differences between varieties on the commercial strawberry field we fitted generalized linear models with variety as fixed effect using quasipoisson distribution considered significant at $P<0.05$ (glm, $F$-test).

RESULTS. In total, strawberry flowers produced 24 volatile compounds. All three varieties emitted all volatile compounds, but differed in the quantities of several compounds (Table 1). The variety Sonata produced highest amounts of $(Z)$ 3-hexenol, methyl salicylate, 6-methyl-5-hepten-2-one, dihydro- $\beta$-ionone, $\beta$-ionone, $\beta$-myrcene, ocimene and $(E, E)$ - $\alpha$-farnesene. The varieties Honeoye and Darselect produced similar quantities of these compounds, except (Z)-3-hexenol, 6-methyl-5hepten-2-one and $(E, E)$ - $\alpha$-farnesene that were more produced by the variety Honeoye. Further, the variety Honeoye produced the highest amounts of lily aldehyde and $\alpha$-copaene. Latter was produced least by the variety Darselect and more by the variety Sonata, while the production of lily aldehyde did not differ between these varieties. The emission of benzyl alcohol, 2-phenyl ethanol, (Z)-3hexenyl acetate and geranyl acetone did not differ between the varieties Honeoye and Sonata, but were significantly lower or differed marginally to the variety Darselect, respectively. The variety Darselect produced intermediate but similar quantities of $\mathrm{d} / \mathrm{l}$ limonene compared to the other varieties, whereas these differed significantly in the emission of this compound. Similar could be observed for the production of 1-Hexanol by the variety Honeoye that produced this compound in 
similar but intermediate quantities, whereas the varieties Sonata and Darselect differed significantly. The compounds p-anisaldehyde and lily aldehyde were emitted in similar quantities by the varieties Darselect and Sonata. While panisaldehyde was less emitted by the variety Honeoye, lily aldehyde was emitted in higher quantities compared the other varieties. The emission of hexanal, heptanal, benzaldehyde, octanal, nonanal, decanal and phenol did not differed between varieties (Table 1).

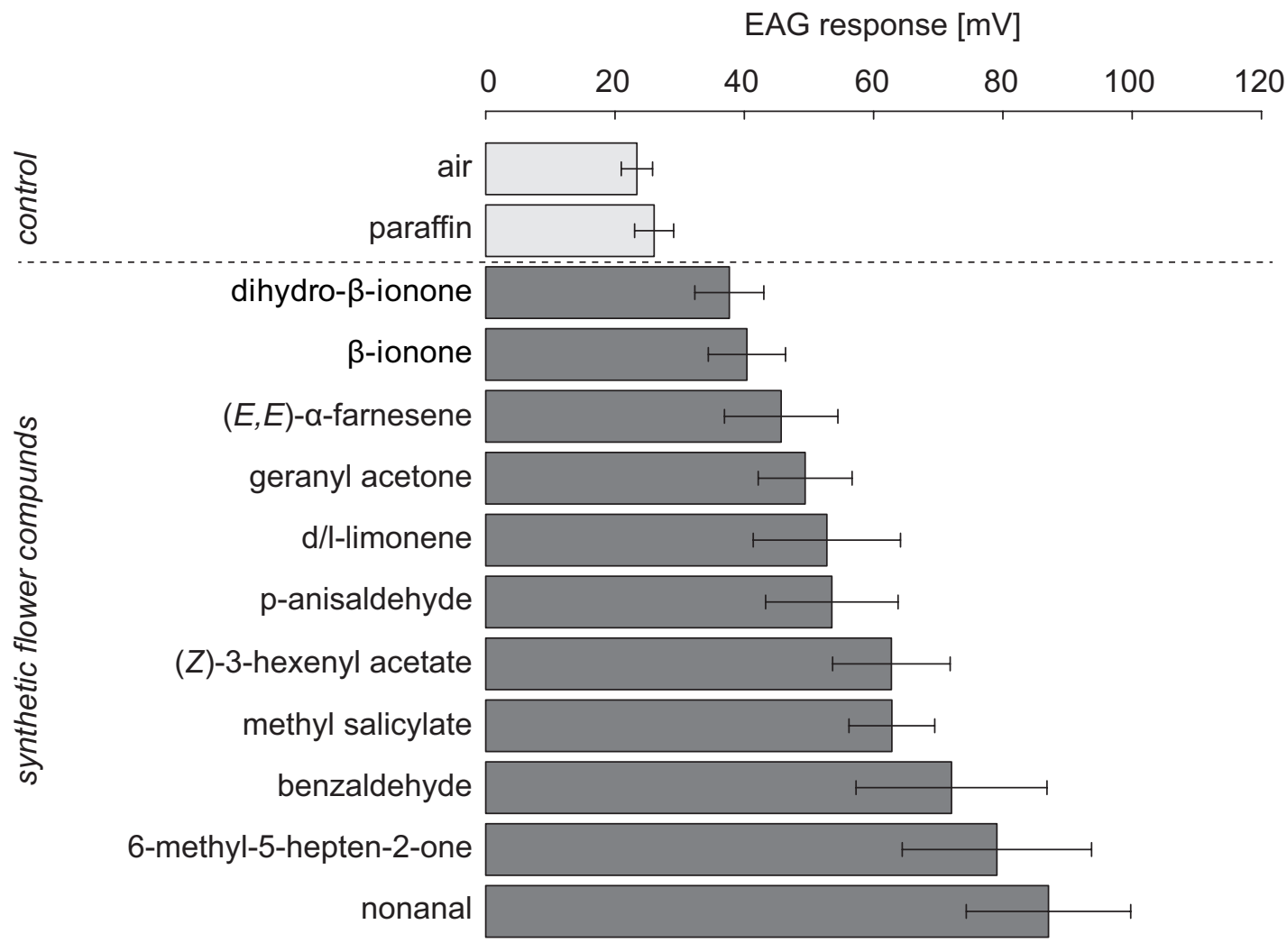

Fig. 1. Antennal responses of naïve $O$. bicornis females to synthetic compounds identified from floral volatile extracts of strawberrv varieties $\left(10^{-3}\right.$ dilution). (mean $\left.\pm S E . n=10\right)$. 
Antennal responses of O. bicornis females were significantly higher to all compounds compared to the controls synthetic air and paraffin oil (Fig. 1). The highest responses were shown on nonanal, 6-methyl-5-hepten-2-one, benzaldehyde, methyl salicylate and (Z)-3-hexenyl acetate. Responses to dihydro- $\beta$-ionone, $\beta$ ionone and $(E, E)-\alpha$-farne-sene differed only slightly but significantly from the con-

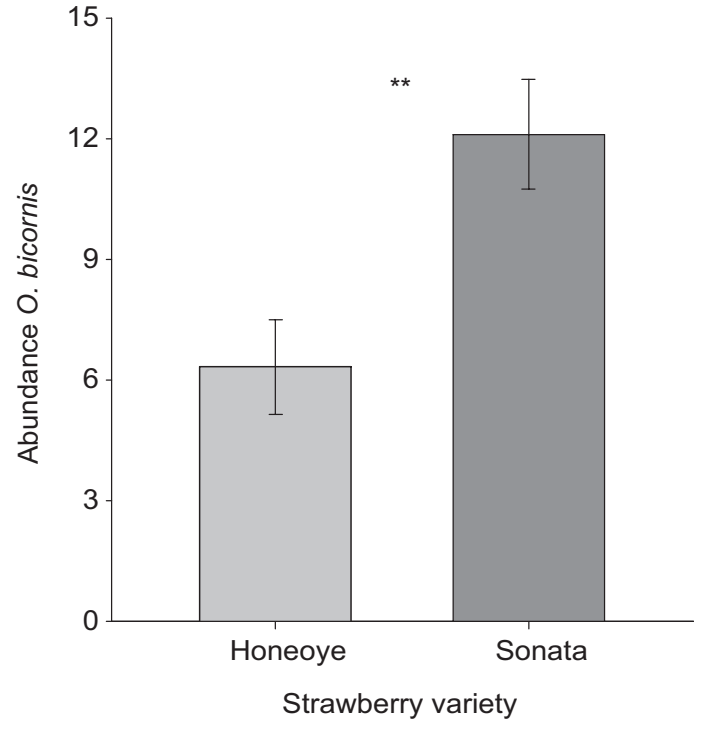

Fig. 2. Abundance differences of 0 . bicornis females between strawberry varieties. Data show mean numbers $( \pm \mathrm{SE})$ of observated specimen per subunit. $P<0.05=$ significant. trol treatments, whereas responses to $\mathrm{p}$-anisaldehyde, $\mathrm{d} / \mathrm{l}$ limonene and geranyl acetone were intermediate. The variety Sonata produced two of the compounds that induced highest bee responses (6-methyl-5-hepten2-one, methyl salicylate) in higher quantities than the other varieties and the compound (Z)-3-hexenyl acetate) in similar quantity to the variety Honeoye. The variety Darselect produced none of the compounds in higher quantities than the other varieties. The varieties Sonata and Honeoye were further tested for their attractiveness to $O$. bicornis on a conventionally managed strawberry field. Females of $O$. bicornis were much more abundant flower visitors on the variety Sonata compared to the variety Honeoye $\left(\mathrm{F}_{1,16}=9.843 ; P=0.006 ;\right.$ Fig. 2$)$. 
DISCUSSION. Here we show for the first time, detailed antennal responses of a generalist wild bee pollinator on a broad spectrum of crop flower volatiles and how different emissions between varieties can influence the bee's visitation rates due to varying responses on distinct compounds.

Strawberry varieties produced the same flower volatile compounds, but differed in volatile quantities. Significant differences between varieties were found for $p$ anisaldehyde, lily aldehye, 1-hexanol, (Z)-3-hexenol, benzyl alcohol, 2-phenyl ethanol, (Z)-3-hexenyl acetate, methyl salicylate, 6-methyl-5-hepten-2-one, dihydro$\beta$-ionone, $\beta$-ionone, $\beta$-myrcene, $\mathrm{d} / \mathrm{l}$-limonene, ocimene, $\alpha$-copaene and $(E, E)-\alpha$ farnesene, whereas emissions of geranyl acetone and $\mathrm{d} / 1$ limonene differed only marginally between varieties. There was no difference between all varieties for the compounds hexanal, heptanal, benzaldehyde, octanal, nonanal, decanal and phenol. Antennal responses of $O$. bicornis females differed between compounds, while the variety Sonata produced higher amounts of two of the five compounds evoking highest responses than the other varieties and was under field conditions visited more frequently than the variety Honeoye.

Compositions and quantities of flower volatile compounds emitted by strawberries have been solely reported by Hamilton-Kemp et al. (1990) so far and show differences compared to our results. Almost two thirds of the compounds we found in the current study (hexanal, heptanal, octanal, nonanal, decanal, lily aldehyde, phenol, 6-methyl-5-hepten-2-one, dihydro- $\beta$-ionone, geranyl acetone, $\beta$-ionone, $\beta$ myrcene, $\alpha$-copaene, $(E, E)$ - $\alpha$-farnesene) have not been found in Hamilton-Kemp et al. (1990) and thus are reported here for strawberries for the first time. In contrast, we did not find the compounds germacrene D and hexyl acetate in our samples. 
However volatile emissions and their differences between strawberry varieties have never been reported before.

All compounds emitted by strawberry flowers are known to be generally emitted by flowers (Knudsen, Tollsten \& Bergström 1993; Knudsen et al. 2006; Dobson 2006). Almost half of the compounds (benzaldehyde, octanal, nonanal, decanal, benzyl alcohol, 2-phenyl ethanol, (Z)-3-hexenyl acetate, 6-methyl-5-hepten-2-one, $\beta$ myrcene, limonene, ocimene) belong even to the most frequently emitted flower volatile compounds (Knudsen et al. 1993; Jürgens, Witt \& Gottsberger 2003; Knudsen et al. 2006; Dobson 2006).

Honeybees are known to respond to several of the tested compounds, namely $(E, E)$ $\alpha$-farnesene (Blight et al. 1997; Le Metayer et al. 1997; Dötterl \& Vereecken 2010), limonene (Henning \& Teuber 1992; Blight et al. 1997), p-anisaldehyde (Theis 2006), (Z)-3-hexenyl acetate (Henning \& Teuber 1992), methyl salicylate (Henning \& Teuber 1992), benzaldehyde (Blight et al. 1997), but some of the found compounds seem also to be attractive to certain wild bees. Bombus terrestris L. responds to ocimene (Mena Granero et al. 2005), Lasioglossum spp. Curt. to panisaldehyde (Theis 2006) and Andrena vaga Panz. to (E,E)- $\alpha$-farnesene (Blight et al. 1997; Dötterl \& Vereecken 2010) and methyl salicylate (Dötterl \& Vereecken 2010).

Antennal responses of females of $O$. bicornis to all volatile compounds were higher as controls, while the responses differed among most compounds. Although Osmia spp. has been reported to respond to floral scents (Howell \& Alarcon 2007), details about certain compounds as in the current study have not been published before. From the five compounds inducing the highest anntenal responses (nonanal, 6methyl-5-hepten-2-one, benzaldehyde, methyl salicylate and (Z)-3-hexenyl acetate), 
two were produced by Sonata in highest quantities (6-methyl-5-hepten-2-one, methyl salicylate). These data suggest decreasing attractiveness of flowers to bees from Sonata over Honeoye to Darselect. This finding could be confirmed for the varieties Sonata and Honeoye growing in a commercial strawberry field, where females of the most abundant wild bee, O. bicornis, visited the variety Sonata much more frequently. Thus the bees' preference appeared to be related to the emitted volatile compounds (Wright \& Schiestl 2009). Although females of O. bicornis responded to the whole variety of compounds, different concentrations of the same compounds lead to different bee responses. This supports the idea that the relative quantity of certain compounds, creating a distinguished blend of volatiles, might be the main driver for the distinctiveness among floral scents (Sachse \& Galizia 2003; Carlsson \& Hansson 2006) and also among strawberry varieties in the current study. Different concentrations of distinct volatile compounds have so far been reported to influence the visitation frequency of honeybees between varieties of sunflowers (Pham-Delegue et al. 1989) and oilseed rape (Wright et al. 2002). However, still practically nothing is known how this is affecting wild bee pollinators and thus these effects are still under discussion (Raguso et al. 2008). Although (E,E)- $\alpha$-farnesene was produced by the varietey Sonata in much higher quantities than all other compounds, antennal responses showed $(E, E)$ - $\alpha$-farnesene belonging to the compounds that were of minor importance for females of $O$. bicornis (dihydro- $\beta$-ionone, $\beta$-ionone, $(E, E)$ - $\alpha$-farnesene). But it is known to be highly attractive for honeybees (Blight et al. 1997; Le Metayer et al. 1997) to which the variety Sonata might be also highly attractive. This may indicate a higher level of specialisation for pollinator species in Sonata compared to the varieties Honeoye and Darselect. 
Although certain strawberry varieties are prefered by bees, all varieties are visited (Skrebtsova 1957; Connor 1975). The varieties Sonata and Honeoye did not differ in the emission of Nonanal, Benzaldehye and (Z)-3-hexenyl-acetate that we found among the five compounds evoking high responses of O. bicornis. Nonanal, benzaldehyde and ( $Z$ )-3-hexenyl acetate belong to the most frequently found flower volatile compounds (Knudsen et al. 1993; Knudsen et al. 2006; Dobson 2006), are typical for generalist flowers (Jürgens et al. 2003) and highly attractive for many pollinators (Dobson 2006).

Our findings are in line with recent reports on the importance of volatile compounds for the flower selection of O. bicornis (Howell \& Alarcon 2007). Wild bees (Klein, Steffan-Dewenter \& Tscharntke 2003; Greenleaf \& Kremen 2006; Winfree et al. 2008; Breeze et al. 2011) and especially Osmia spp. (Holzschuh et al. 2012; Jauker et al. 2012) have been suggested to be major pollinators of crops and can affect the fitness of plants (Majetic, Raguso \& Ashman 2009).

CONCLUSIONS. Volatile compounds of crop flowers were important in attracting wild bees for sustaining pollination services. To our knowledge, only two studies (Beker et al. 1989; Rodriguez-Saona et al. 2011) have so far been shown volatile mediated differences of pollinator attraction between crop varieties and the importance for the visitation by solitary wild bees. As varieties of strawberries and other crops differ in the emission of flower volatile compounds, differences in bee visitation rates can be expected to affect pollination success and thereby, yield and quality (Dötterl \& Vereecken 2010). Different bee species improve strawberry pollination by complementary behaviour (Chagnon et al. 1993) and sufficient 
strawberry pollination needs the services of honeybees and wild bees (Chapter 5). Hence, breeding strawberry varieties and also the farmers' selection of varieties should focus more on flower volatiles triggering fruit set and market value by the attraction of several pollinator species. 


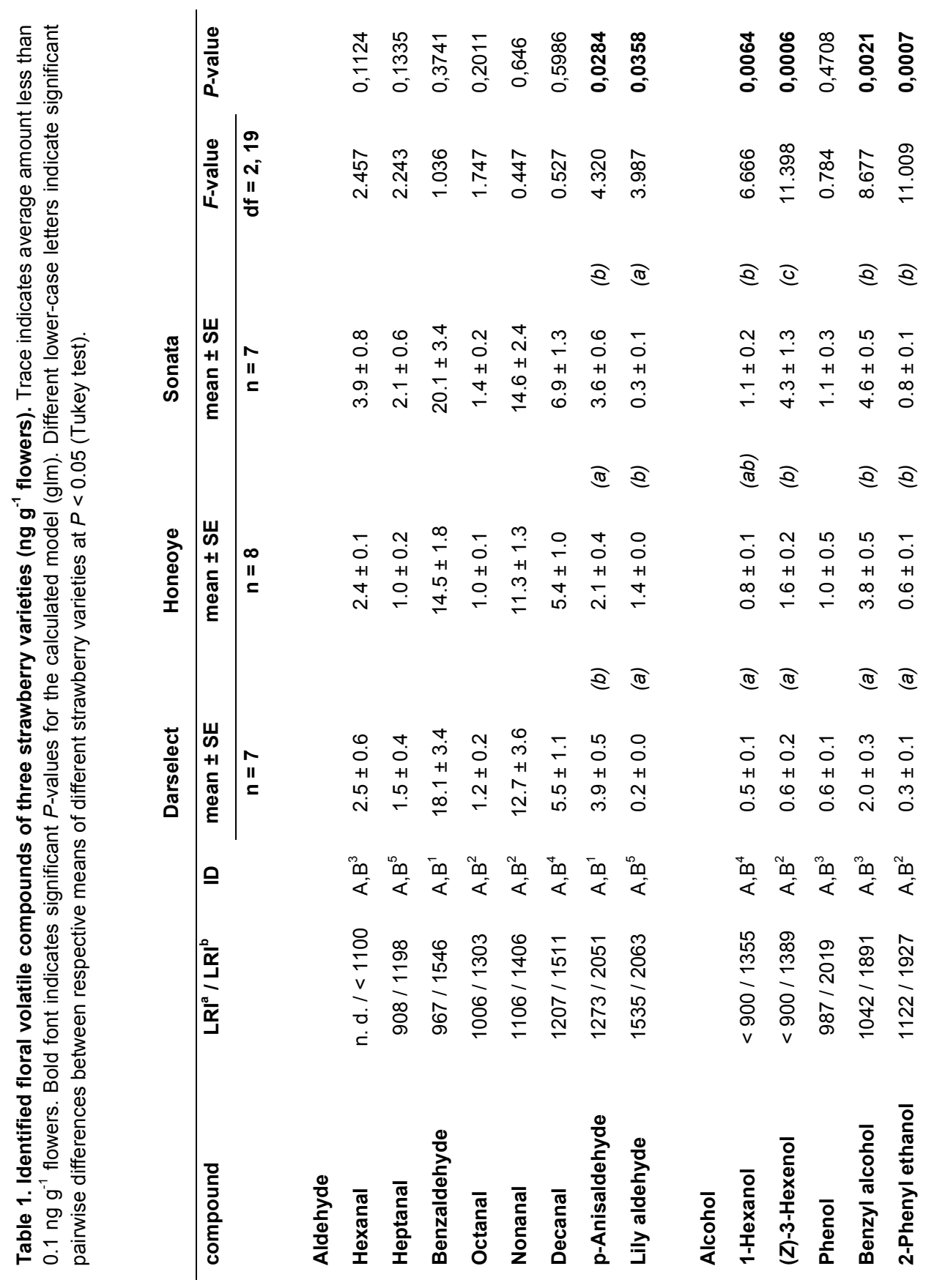




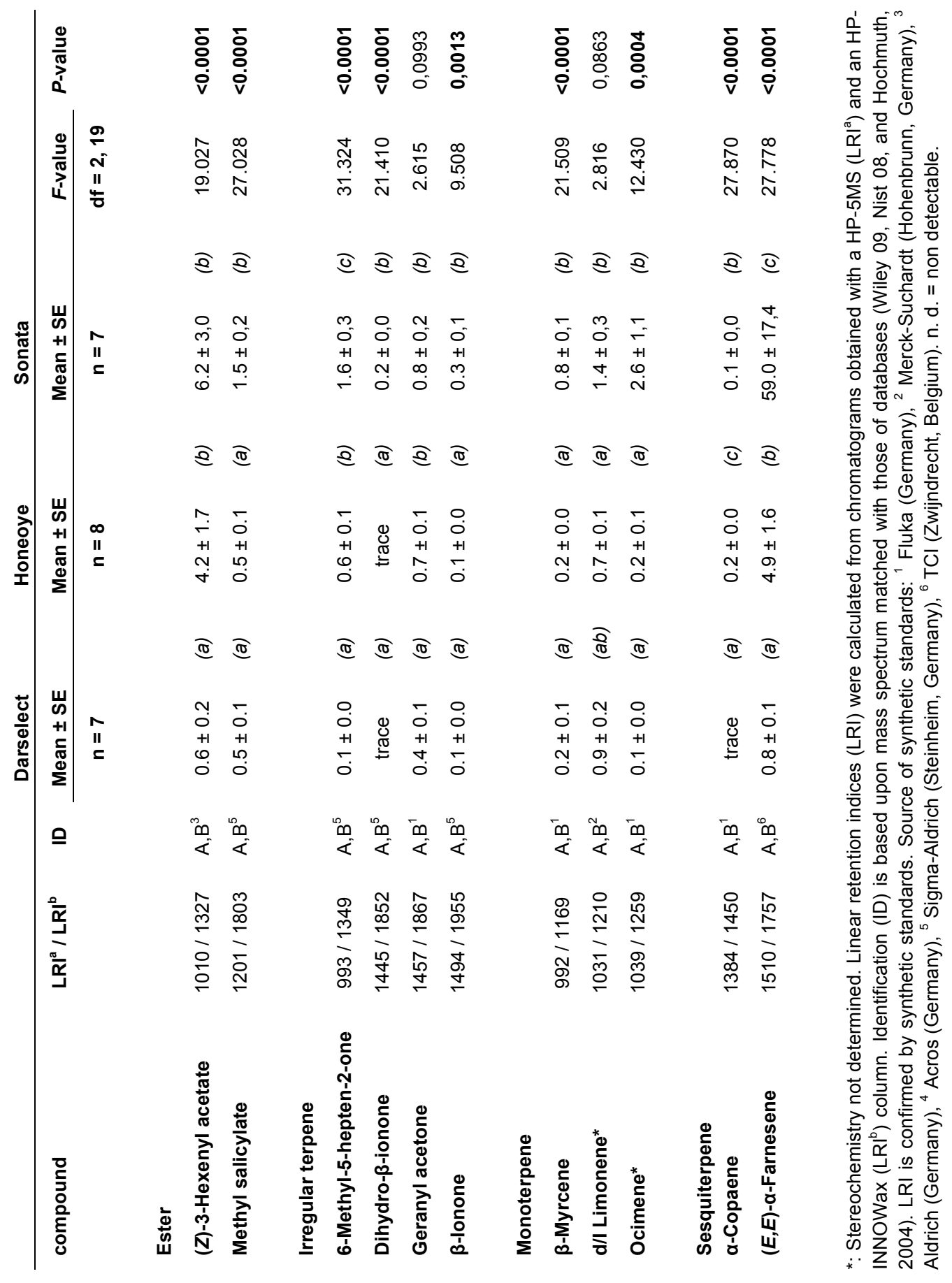


ACKNOWLEDGMENTS. The authors thank S. Schütz for the provision with laboratory equipment and greenhouse space and S. Nicke for laboratory assistance; thanks to U. Kierbaum for assistance in the field. We thank G. Everwand for comments and discussions on the manuscript. This work has been fundet by the German Research Foundation (DFG; TS 45/29-1).

\section{REFERENCES}

Adler, L.S. \& Irwin L.E. (2012) What you smell is more important than what you see? Natural selection on floral scent. New Phytologist, 195, 510-511.

Anderson, D., East, I.J., Cox-Foster, D., Conlan, S., Holmes, E.C., Palacios, G., Kalkstein, A., Evans, J.D., Moran, N.A., Quan, P.L., Geiser, D., Briese, T., Hornig, M., Hui, J., Vanengelsdorp, D., Pettis, J.S. \& Lipkin, W.I. (2008) The latest buzz about colony collapse disorder. Science, 319, 724-725.

Ashman, T.L., Bradburn, M., Cole, D.H., Blaney, B.H. \& Raguso, R.A. (2005) The scent of a male: the role of floral volatiles in pollination of a gender dimorphic plant. Ecology, 86, 2099-2105.

Beker, R., Dafni, A., Eisikowitsch, D. \& Ravid, U. (1989) Volatiles of two chemotypes of Majorana sysriaca L. (Labiatae) as olfactory cues for the honeybee. Oecologica, 79, 446-451.

Biesmeijer, J.C., Roberts, S.P.M., Reemer, M., Ohlemüller, R., Edwards, M., Peeters, T., Schaffers, A.P., Potts, S.G., Kleukers, R., Thomas, C.D., Settele, J. \& Kunin, W.E. (2006) Parallel declines in pollinators and insect pollinated plants in Britain and the Netherlands. Science, 313, 351-354. 
Blight, M.M., Le Metayer, M., Pham-Delegue, M.-H., Pickett, J.A., Marion-Poll, F., \& Wadhams, L.J. (1997) Identification of floral volatiles involved in recognition of oilseed rape flowers, Brassica napus, by honeybees, Apis mellifera. Journal of Chemical Ecology, 23, 1715-1727.

Breeze, T.D., Bailey, A.P., Balcombe, K.G. \& Potts, S.G. (2011) Pollination services in the UK: How important are honeybees? Agriculture, Ecosystems and Environment, 142, 137-143.

CPVO - Community Plant Variety Office of the European Union (2012). http:// www.cpvo.europa.eu/main/en.

Chagnon, M., Gingras, J. \& de Oliveira, D. (1993) Complementary aspects of strawberry pollination by honey and indigenous bees (Hymenoptera). Journal of Economic Entomology, 86, 416-420.

Carlsson, M.A. \& Hansson, B.S. (2006) Detection and coding of flower volatiles in nectar-foraging insects. Biology of Floral Scent (eds N. Dudareva \& E. Pichersky), pp. 243-261. CRC Press, Taylor \& Francis Group, Boca Raton FL, USA.

Chess, S.K.R., Raguso, R.A. \& LeBuhn, G. (2008) Geographic divergence in floral morphology and scent in Linanthus dichotomus (Polemoniaceae). American Journal of Botany, 95, 1652-1659.

Cheong, M.W., Loke, X.Q., Liu, S.Q., Pramudya, K., Curran, P., \& Yu, B. (2011) Characterization of volatile compounds and aroma profiles of malaysian pomelo (Citrus grandis (1.) osbeck) blossom and peel. Journal of Essential Oil Research, 23, 34-44.

Connor, L.J. (1975) The role of cultivar in insect pollination of strawberries. Proceedings of the 3rd International Symposium on Pollination, 149-154. 
Dobson, H.E.M. (2006) Relationship between floral fragrance composition and type of pollinator. Biology of Floral Scent (eds N. Dudareva \& E. Pichersky), pp. 147-198. CRC Press, Taylor \& Francis Group, Boca Raton, Fl, USA.

Dötterl, S., Wolf, L.M. \& Jürgens A. (2005) Qualitative and quantitative analyses of flower scent in Silene latifolia. Phytochemistry, 66, 203-213.

Dötterl, S. \& Vereecken, N.J. (2010) The chemical ecology and evolution of beeflower interactions: a review and perspectives. Canadian Journal of Zoology, 88, 668-697.

Free, J.B. (1993) Insect Pollination of Crops. Academic Press, London, UK.

Godfray, H.J.C. (2010) Food security: the challenge of feeding 9 billion people. Science, 327, 812-818.

Greenleaf, S.S. \& Kremen, C. (2006) Wild bee species increase tomato production and respond differently to surrounding land use in Nothern California. Biological Conservation, 133, 81-87.

Hamilton-Kemp, T.R., Loughrin, J.H. \& Anderson, R.A. (1990) Identification of some volatile compounds from strawberry flowers. Phytochemistry, 29, 28472848 .

Henning, J.A. \& Teuber, L.R. (1992) Combined gas chromatographyelectroantennogram characterization of alfalfa floral volatiles recognized by honey bees (Hymenoptera: Apidae). Entomological Society of America, 85, $226-232$.

Holzschuh, A., Dudenhöffer, J.-H. \& Tscharntke T. (2012) Landscapes with wild bee habitats enhance pollination, fruit set and yield of sweet cherry. Biological Conservation, 153, 101-107. 
Howell, A.D. \& Alarcon, R. (2007) Osmia bees (Hymenoptera: Megachilidae) can detect nectar-rewarding flowers using olfactory cues. Animal Behaviour, 74, 199-205.

Hsu, J.C. (1996) Multiple comparison: Theory and Method. Chapman and Hall, London. U.K.

Jauker, F., Bondarenko, B., Becker, H.C. \& Steffan-Dewenter, I. (2012) Pollination efficiency of wild bees and hoverflies provided to oilseed rape. Agricultural and Forest Entomology, 14, 81-87.

Jürgens, A., Witt, T. \& Gottsberger, G. (2003) Flower scent composition in Dianthus and Saponaria species (Caryophyllaceae) and its relevance for pollination biology and taxonomy. Biochemical Systematics and Ecology, 31, $345-357$.

Kessler, A. \& Halitschke, R. (2009) Floral scent in a whole-plant context. Testing the potential for conflicting selection on floral chemical traits by pollinators and herbivores: predictions and case study. Functional Ecology, 23, 901-912.

Klein, A.-M., Steffan-Dewenter, I. \& Tscharntke, T. (2003) Bee pollination and fruit set of Coffea arabica and C. canephora (Rubiaceae). American Journal of Botany, 90, 153-157.

Klein, A.-M., Vaissiere, B.E., Cane, J.H., Steffan-Dewenter, I., Cunningham S.A., Kremen, C. \& Tscharntke, T. (2007) Importance of pollinators in changing landscapes for world crops. Proceedings of the Royal Society of London B, 274, 303-313.

Knudsen, J.T., Tollsten, L. \& Bergström, L.G. (1993) Floral Scents - a checklist of volatile compounds isolated by head-space techniques. Phytochemistry, 33, 253-280. 
Knudsen, J.T., Eriksson, R., Gershenzon, J. \& Stahl, B. (2006) Diversity and distribution of floral scent. Botanical Review, 72, 1-120.

Lautenbach, S., Seppelt, R., Liebscher, J. \& Dormann, C.F. (2012) Spatial and temporal trends of global pollination benefit. PLoS ONE, 7, e35954.

Le Metayer, M., Marion-Poll, F., Dandoz, J.C., Pham-Delegue, M.H., Blight, M.M., Wadhams, L.J., Masson, C. \& Woodcock, C.M. (1997). Effect of conditioning on discrimination of oilseed rape volatiles by the honeybee: use of a combined gas chromatography-proboscis extension behavioural assay. Chemical Senses, 22, 391-398.

Majetic, C.J., Raguso, R.A. \& Ashman, T.-L. (2009) The sweet smell of success: floral scent affects pollinator attraction and seed fitness in Hesperis matronalis. Functional Ecology, 23, 480-487.

Mayer, C., Adler, L., Armbruster, W.S., Dafni, A., Eardley, C., Huang, S.-Q., Kevan, P.G., Ollerton, J., Packer, L., Ssymank, A., Stout, J.C. \& Potts, S.G. (2011) Pollination ecology in the 21st century: key questions for future research. Journal of Pollination Ecology, 3, 8-23.

McLafferty, F.W. (2009) Registry of Mass Spectral Data combined with NIST / EPA / NIH database 2008. Wiley-Blackwell, Hoboken, NJ, USA.

Mena Granero, A.M., Sanz, J.M.G., Gonzalez F.J.E., Vidal, J.L.M., Dornhaus, A., Ghani, J., Serrano, A.R. \& Chittka, L. (2005) Chemical compounds of the foraging recruitment pheromone in bumblebees. Naturwissenschaften, 92, $371-374$.

Parachnowitsch, A.L. \& Kessler, A. (2010) Pollinators exert natural selection on flower size and floral display in Penstemon digitalis. New Phytologist, 188, 393-402. 
Parachnowitsch, A.L., Raguso, R.A. \& Kessler, A. (2012) Phenotypic selection to increase floral scent emission, but not flower size or colour in bee-pollinated Penstemon digitalis. New Phytologist, 195, 667-675.

Pham-Delegue, M.H., Etievant, P., Guichard, E. \& Masson, C. (1989) Sunflower volatiles involved in honey bee discrimination among genotypes and flowering stages. Journal of Chemical Ecology, 15, 329-343.

Potts, S.G., Biesmeijer J.C., Kremen, C., Neumann, P., Schweiger, O. \& Kunin, W.E. (2010) Global pollinator declines: trends, impacts and drivers. Trends in Ecology and Evolution, 25, 345-353.

Raguso, R.A. (2008) Wake up and smell the roses: the ecology and evolution of floral scent. Annual Review of Ecology, Evolution and Systematics, 39, 549569.

R Development Core Team (2011) R: A language and environment for statistical computing. $R$ foundation for statistical computing. http://www.R-project.org.

Reinhard, J. \& Srinivasan, M.V. (2009) Role of scents in honeybee foraging and recruitment. Food exploitation by social insects. (eds M. Hrncir \& C. Jarau), pp. 165-182. CRC Press, NewYork, NY, USA.

Robertson, G.W., Griffiths, D.W., Macfarlane-Smith, W. \& Butcher, R.D. (1993) The application of thermal desorption-gas chromatography-mass spectrometry to the analyses of flower volatiles from five varieties of oilseed rape (Brassica napus spp. oleifera). Phytochemical Analysis, 4, 152-157.

Rodriguez-Saona, C., Parra, L., Quiroz, A. \& Isaacs, R. (2011) Variation in highbush blueberry floral volatile profiles as a function of pollination status, cultivar, time of day and flower part - implications for flower visitation by bees. Annals of Botany, 107, 1377-1390. 
Sachse, S. \& Galizia, C.G. (2003) The coding of odour-intensity in the honeybee antennal lobe: local computation optimizes odour representation. European Journal of Neuroscience, 18, 2119-2132.

Skrebtsova, N.D. (1957) The role of bees in pollinating strawberries. Pchelovodstvo, 34, 34-36.

Soler, C., Hossaert-McKey, M., Buatois, B., Bessiere, J.-M., Schatz, B. \& Proffit, M. (2011) Geographic variation of floral scent in a highly specialized pollination mutualism. Phytochemistry, 72, 74-81.

Theis, N. (2006) Fragrance of Canada thistle (Cirsium arvense) attracts both floral herbivores and pollinators. Journal of Chemical Ecology, 32, 917-927.

Tholl, D., Boland, W., Hansel, A., Loreto, F., Röse, U.S.R. \& Schnitzler J.-P. (2006) Practical approaches to plant volatile analyses. The Plant Journal, 45, 540560.

Tscharntke , T., Clough, Y., Wanger, T.C., Jackson, L. Motzke, I., Perfecto, I.,Vandermeer, J. \& Whitbread, A. (2012) Global food security, biodiversity conservation and the future of agricultural intensification. Biological Conservation, 151, 53-59.

Van den Dool, H. \& Kratz, P.D. (1963) A generalization of the retention index system including linear temperature programmed gas-liquid partition chromatography. Journal of Chromatography, 11, 463-471.

Venables, W.N. \& Ripley, B.D. (2002) Modern applied statistics with S. Springer, New York, NY, USA.

Weissbecker, B., Holighaus, G. \& Schütz, S. (2004) Gas chromatography with mass spectrometric and electroantennographic detection: analysis of wood odorants 
by direct coupling of insect olfaction and mass spectrometry. Journal of Chromatography A, 1056, 209-216.

Winfree, R., Williams, N.M., Gaines, H., Ascher, J.S. \& Kremen, C. (2008) Wild bee pollinators provide the majority of crop visitation across land-use gradients in New Jersey and Pennsylvania, USA. Journal of Applied Ecology, 45, 793-802.

Wright, G.A., Skinner, B.D. \& Smith, B.H. (2002) Ability of honeybee, Apis mellifera, to detect and discriminate odors of varieties of canola (Brassica rapa and Brassica napus) and snapdragon flowers (Antirrhinum majus). Journal of Chemical Ecology, 28, 721-740.

Wright, G.A. \& Schiestl, F.P. (2009) The evolution of floral scent: the influence of olfactory learning by insect pollinators on the honest signalling of floral rewards. Functional Ecology, 23, 841-851. 


\section{Chapter 5}

Context-dependent importance of honeybee vs. wild bee pollination from crop field edges to centres

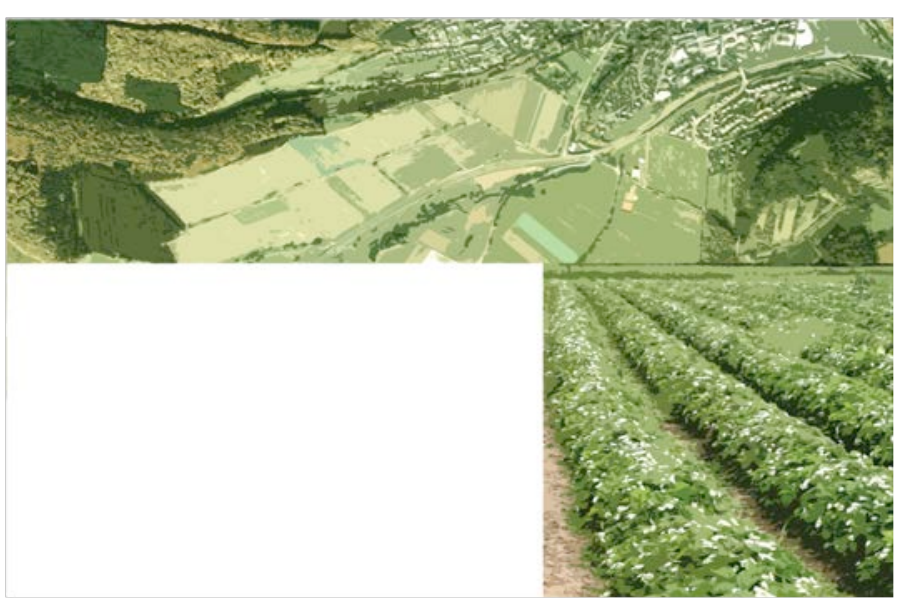




\section{SUMMARY}

1. Crop pollination is mainly conducted by bees, but the relative importance of honeybees (Apis mellifera L.) or wild bees and their potential differences in responses to within-crop field heterogeneity is unclear.

2. We analysed how diversity and abundance of bees changed from strawberry field edges, to the strawberry-dominated field centre. Evenness and Shannondiversity were hypothesized to be of higher functional importance for complementary pollination and final crop yield than abundance and richness of bees. Strawberry fruits and bees pollinating strawberry flowers were collected at transects from the edge to the centre of commercial strawberry fields.

3. Strawberries were visited by 24 bee species with Apis mellifera L. being most abundant. Fruit weight was best explained by Evenness, less well by Shannon-diversity and least by species richness and bee abundance.

4. The relationship between pollinator community structure and yield contrasted between field edge and centre. Strawberry pollination at the field edge was most efficient when provided by evenly distributed bee communities, whereas dominance of $A$. mellifera was most efficient at the field centre.

5. This changing importance of honeybees was supported by higher heterospecific pollen loads carried by $A$. mellifera at the field edge and higher loads of strawberry pollen in the field centre.

6. Synthesis and applications. Honeybees and wild bees are both needed for strawberry pollination, as their relative importance changes from the field edge to the centre. Efficient pollination of strawberries cannot be restricted to 
honeybees because of this context dependency of honeybee pollination success. Protection and enhancement of wild bee species, coping with crop field heterogeneity, is needed to maintain high overall crop pollination levels as an important ecosystem service.

KEY-WORDS: conspecific pollen load, flower constancy, biodiversity, ecosystem service, Evenness, field heterogeneity, fruit weight, heterospecific pollen load, species richness, strawberries. 
INTRODUCTION. Bees are the most important pollinators in most cropping systems (Roubik 1995, 2002; Klein et al. 2007; Dötterl \& Vereecken 2010). Crop pollination often relies solely on honeybees (Klein et al. 2007). However, solitary and social wild bees can also provide pollination for crops (e.g. Klein, SteffanDewenter \& Tscharntke 2003; Greenleaf \& Kremen 2006). In several cases, wild bees have been shown to be even more abundant (Winfree et al. 2008) and more important (Breeze et al. 2011) than honeybees. However, recent views are contradictory whether wild bees or honeybees are most important for crop pollination services (Corbet 1991a, b; Morse 1991; Ollerton et al. 2012; Aebi et al. 2012).

Insect pollination is known to greatly increase crop yield and quality (Free 1993), and most crops are pollinated by many pollinator species (Free 1993), but the role of changing pollinator community composition is still unclear. While bee abundance and species richness can have positive effects on pollination of several crops other crops seem to be more influenced by the community composition of bees (Klein et al. 2007). For example, pollination and fruit set of Coffea arabica (Klein et al. 2003) and Cucurbita moshata (Hoehn et al. 2008) is best explained by the species richness, not the abundance of bees.

Complementary benefits of bees have been also shown for strawberry flowers differing in spatial positions on the plant (Chagnon, Gingras \& Oliveira 1993). Kakutani et al. (1993) found honeybees to be more effective for strawberry pollination than solitary wild bees, because of high numbers of individuals. Following Williams \& Thomson (2001), honeybees are less effective, whereas Albano et al. (2009) report that single visits of different bee species contribute 
equally to strawberry pollination. Thus the patterns of strawberry pollination are still not fully understood.

The aim of our study was to identify the main drivers and patterns of strawberry pollination by bees in conventional strawberry fields. We used abundance, species richness, Shannon-diversity and Evenness of bees along transects from edge to centre of commercial strawberry fields to assess the influence of bee communities on fruit weight of strawberries in relation to field location. Pollen loads of the most common strawberry pollinator A. mellifera were collected to analyse its flower constancy in strawberry pollination. We hypothesized that the community composition of bees and its role for pollination changes in dependence on the location on the field. We expected Evenness and Shannon-diversity to be the best predictors of strawberry fruit weight due to complementary effects in strawberry pollination.

MATERIAL \& METHODS. The study was conducted on seven conventional strawberry fields in the vicinity of Göttingen in 2010. Strawberry varieties can differ in their attraction to bee pollinators (Abrol 1992), thus only one variety - Honeoye was used on all study sites. This variety flowers at the same time as oilseed rape (Brassica napus L.).

Bees pollinating strawberry flowers were collected at four transects from field edge to centre, using sweep nets. Two transects were positioned at the field edge, the first at the field corner (field position one), the second in the middle of the crop row adjacent to the field edge (field position two). The two other transects were positioned in the field, one in the field middle (field position four), the other 
(position three) in equal distance between field positions two and four. Distances between field positions varied due to different field sizes. Each transect consisted of two adjacent strawberry rows at a length of 100 plants and was sampled twice for 30 minutes in the morning and 30 minutes in the afternoon. Morning and afternoon samples on the same field were applied on different days. Morning and afternoon samples were pooled and bee abundance, species richness, Shannon-diversity and Evenness were calculated for each field position and used for statistical analysis.

Pollen was sampled from honeybees. All pollen loads were sampled as follows. After removal of pollen baskets, individual bees were placed in Eppendorf tubes with distilled water and a drop of detergent. They were then vortexed to dislodge pollen from the body, and removed from the tube for pinning and identification. Samples were then centrifuged (Centrifuge 5403, Eppendorf, Engelsdorf, Germany) for five minutes at 3,000 rpm. The resulting pollen pellet was then air dried and frozen for later analysis. For counting, three subsamples were taken from each pellet, by mixing the pellet with a sterile metal dissection instrument, and scraping a small amount of pollen onto a microscope slide. A small square (c. $5 \times 5 \mathrm{~mm}$ ) of fuchsin jelly was then melted onto the pollen sample, and covered with a cover slip, thus staining and preparing it for identification and counting with a light microscope. Oilseed rape pollen was identified in addition to strawberry pollen, because oilseed rape played a major role in the surroundings of the strawberry fields. Oilseed rape pollen was not clearly distinguishable from other Brassica species, but other Brassica species were comparatively rare at the sites.

After anthesis, two plants per transect were covered with gauze-bags to protect the fruits from pest damage and hand picking by consumers. All fruits from three stems per plant were harvested when fully ripe and weighted. Mean fruit weight was 
calculated per plant while considering consecutive flowering periods, which result in different fruit weight.

Statistical analyses were carried out using the software R, Version 2.13.2 (R Development Core Team, 2011). Bee abundance, species richness, Shannondiversity and Evenness were calculated for each field and field position. The influence of each parameter on strawberry fruit weight was assessed by fitting linear mixed effects models ("Ime"-function in package "nlme"; Pinheiro \& Bates 2002)
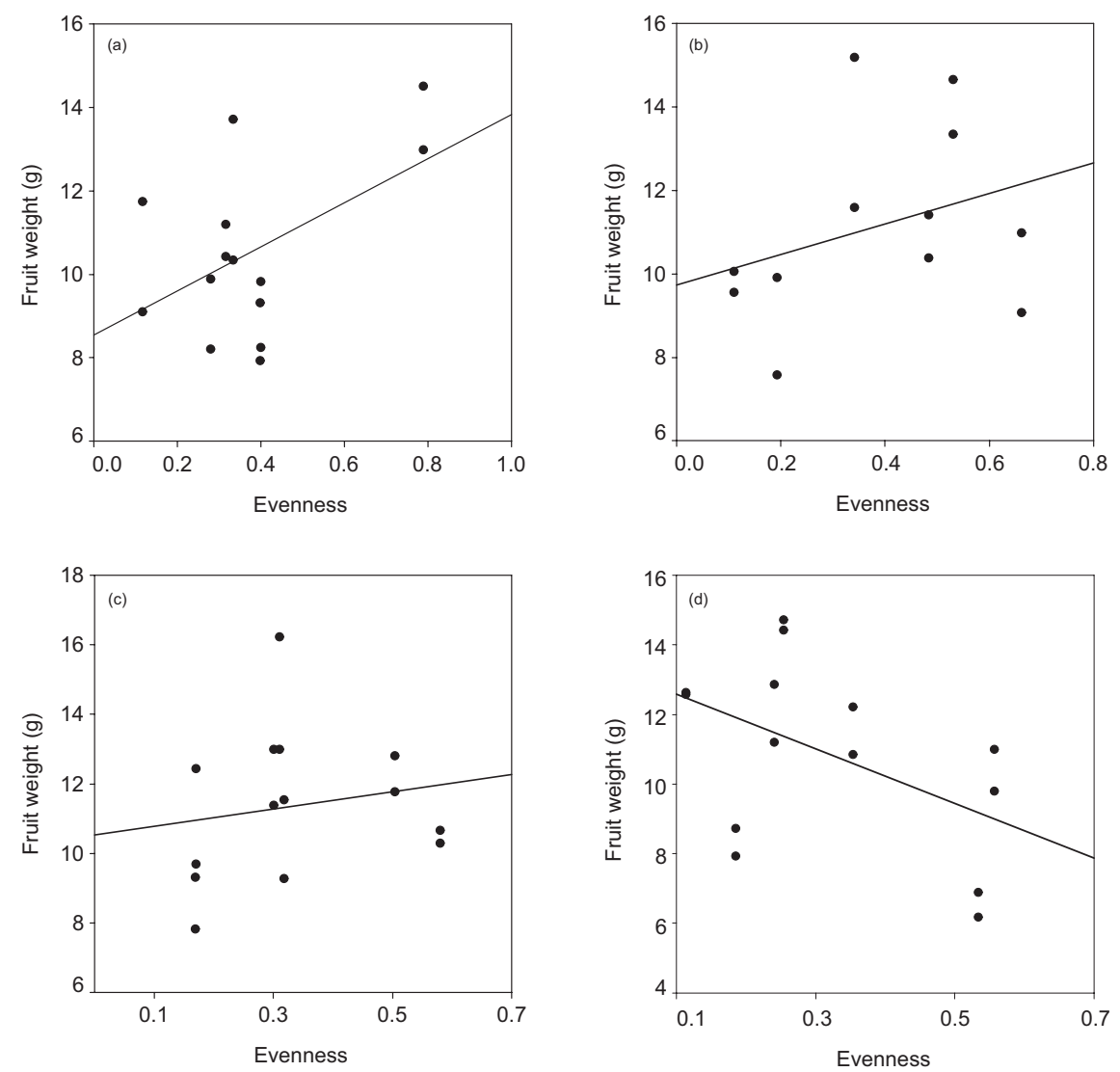

Fig. 1. Evenness of bee communities in relation to strawberry fruit weight. Effects differed between field positions (from edge to centre, i.e. field positions one to four). (a) Field position one (edge). (b) Field position two. (c) Field position three. (d) Field position four (centre). 
with mean fruit weight per plant versus each diversity parameter in interaction with field position. Study site was used as random effect to account for location variations. Residuals were inspected for non-normality and heterogeneity and data were transformed to meet assumptions of heterogeneity and normality where necessary. Models were simplified and bee abundance and diversity parameters were compared for their explanatory power on strawberry fruit weight using second order Akaike's Information Criterion (“AICc"-function in package "MuMIn"; Burnham \& Anderson 2002). Models which AICc values differed less than seven were further compared for their likeliness ("model.sel"-function in the package "MuMIn"; Barton 2009).

The results of the above models were refitted using restricted maximum likelihood and inspected to determine whether bee abundance or diversity parameters generally influenced strawberry fruit weight or whether their influence were dependent on field positions.

RESULTS. In total, 1584 fruits were harvested and 805 bees from 24 species were collected. Honeybees (A. mellifera) were most abundant (63.2\%), followed by Bombus terrestris L. (16.0\%), B. lapidarius L. (3.8 \%) Andrena nigroaenea Kirby $(3.7 \%)$ and Osmia bicornis L. (3.6\%).

Strawberry fruit weight was best explained by Evenness, whereas Shannon-diversity $($ delta $\mathrm{AICc}=2.67)$, species richness $($ delta $\mathrm{AICc}=7.45)$ and abundance $($ delta AICc $=13.06)$ were less explanatory. As AICc values between models of Evenness and Shannon-diversity differed less than seven, they were compared for their likeliness. The Evenness model was almost four times as likely as the Shannon-diversity model 
(0.794 versus 0.206$)$ confirming a much higher explanatory power of Evenness on strawberry fruit weight.

Effects of Evenness on strawberry fruit weight significantly varied between field positions $\left(F_{3,40}=5.021 ; P=0.005\right.$; Fig. 1$)$. Whereas Evenness had a positive effect on fruit weight at the field edge (field position one), this effect became smaller with increasing distance to the edge in field positions two and three and became even

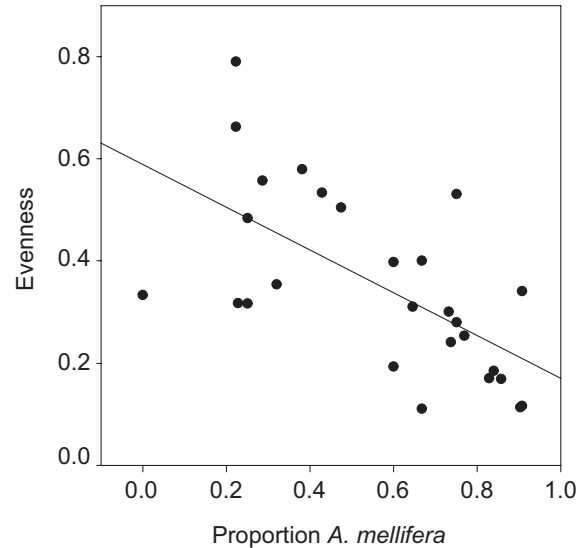

Fig. 2. Proportion of $A$. mellifera in relation to bee community Evenness. The proportion of $A$. mellifera negatively affected Evenness and, on average, did not differ between field positions. negative in the field centre (field position four). Similar effects were found for Shannon-diversity $\left(F_{3,40}=4.097 ; P=0.013\right.$; see Fig. S1 in Supplementary Information). Effects of bee species richness $\left(F_{3,42}=\right.$ 4.754; $P=0.006$; see Fig. S2 in Supplementary Information) and bee abundance $\left(F_{3,42}=2.999 ; P=0.041\right.$; see Fig. $\mathrm{S} 3$ in Supplementary Information) on fruit weight significantly differed between field positions, but were inconsistent. The diversity parameters did not have a general relation to fruit weight (Evenness: $F_{1,40}=$ 0.781; $P=0.382$; Shannon-diversity: $F_{1,40}=0.004 ; P=0.3992$; species richness: $F_{1,42}=0.393 ; P=0.534$; abundance: $\left.F_{1,42}=0.583 ; P=0.449\right)$ of strawberries, and could not explain the differences in fruit weight along the edge-centre field positions.

Proportions of the most abundant bee species A. mellifera were calculated for each field position and related to Evenness by fitting linear mixed effects models. 
Increasing proportions of $A$. mellifera generally decreased Evenness $\left(F_{1,19}=7.991\right.$; $P=0.011$; Fig. 2), without differing between field positions. There was no overall effect of the proportion of $A$. mellifera on strawberry fruit weight $\left(F_{1,42}=0.044 ; P=\right.$ $0.835)$, but its effects were contrasting between field edge and centre $\left(F_{3,42}=4.807\right.$; $P=0.006$; Fig. 3). Fruit weight at the field edge (field position one) was much lower
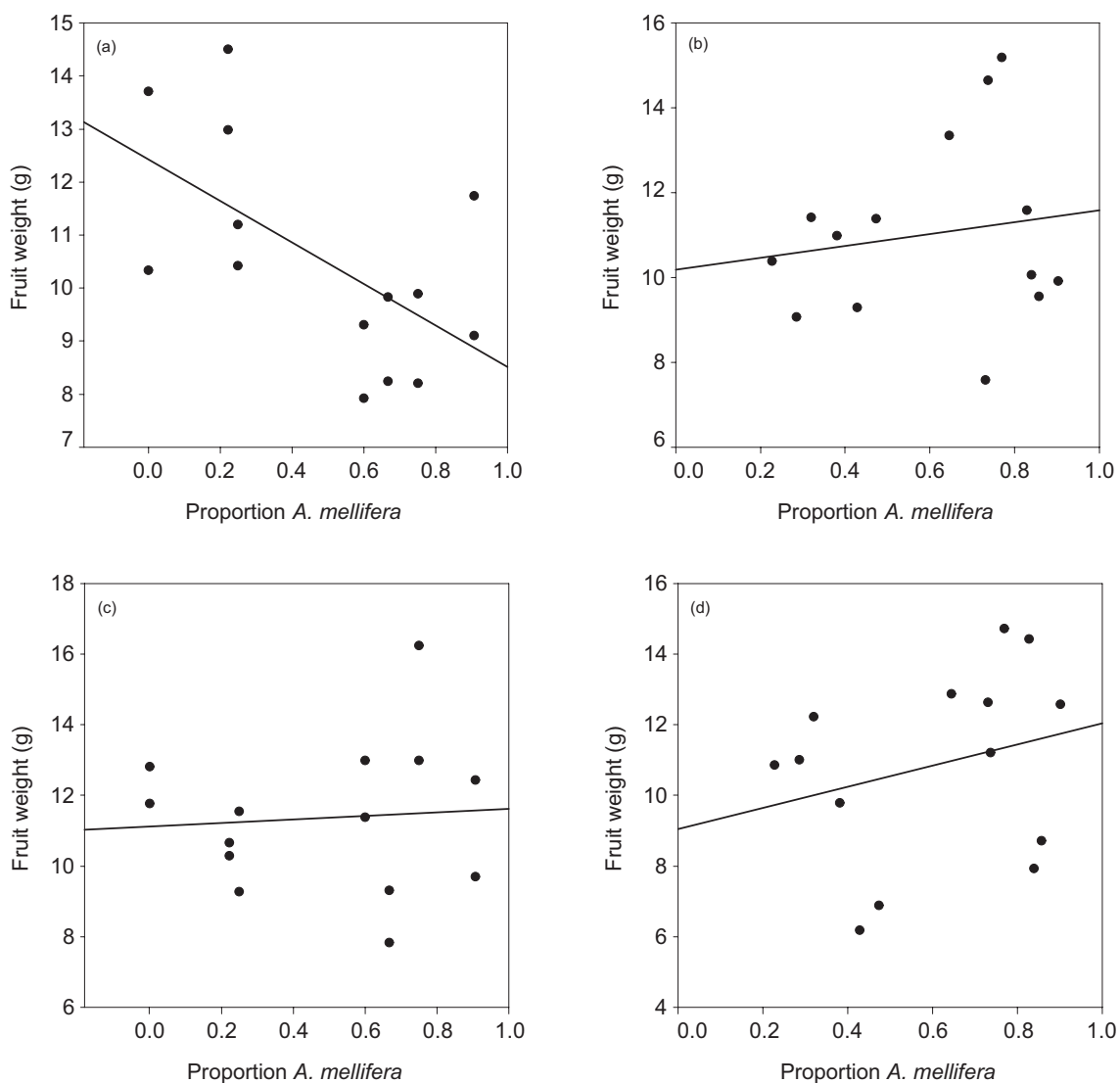

Fig. 3. Proportion of honeybees in relation to strawberry fruit weight. Effects differed between field positions (from edge to centre, i.e. field positions one to four). (a) Field position one (edge). (b) Field position two. (c) Field position three. (d) Field position four (centre). 
in cases of higher proportions of A. mellifera. Field position two showed a slightly positive effect, field position three a slightly negative effect. In contrast, fruit weight at the field centre (field position four) increased with higher proportions of $A$. mellifera.

Comparisons of pollen loads of $A$. mellifera between field positions showed that the proportion of strawberry (conspecific) pollen was lowest at the field edge and successively increased with increasing distance to the field edge until it reached a maximum of $97 \%$ at the field centre (Fig. 4). The second most abundant pollen was from oilseed rape. In contrast to strawberry pollen, the proportion of oilseed rape pollen decreased with increasing distance from the field edge (Fig. 4). Proportions of strawberry pollen and oilseed rape pollen were negatively correlated between transects (Spearman's correlation $=-0.79 ; P<0.001)$.
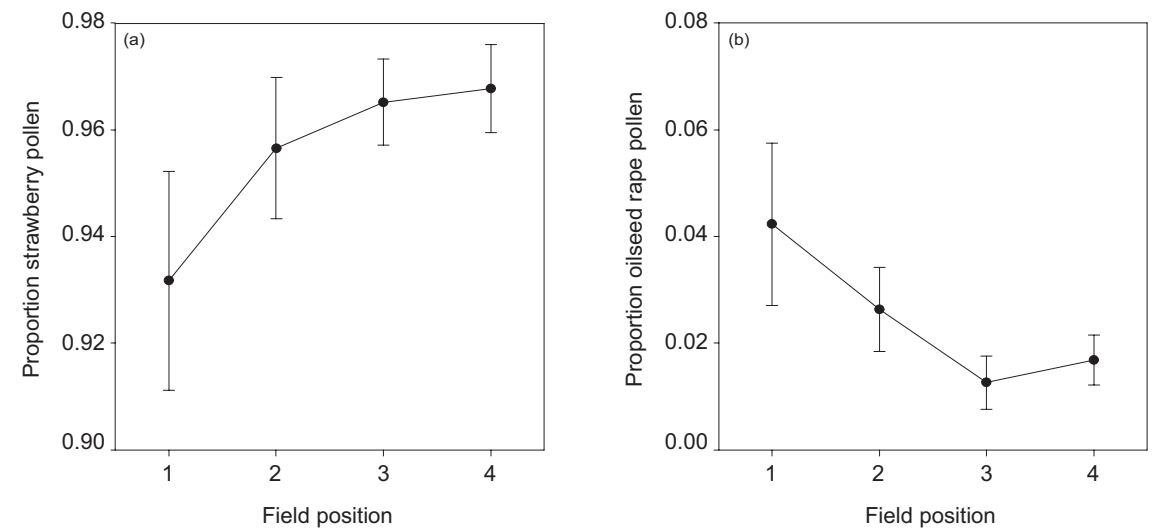

Fig. 4. Pollen loads of $\boldsymbol{A}$. mellifera in dependence on field positions. (a) Proportion of strawberry pollen depended on field location (from edge to centre, i.e. field positions one to four). (b) Proportion of oilseed rape pollen dependent on field location (field positions one to four). Error bars show standard errors. 
DISCUSSION. Our results showed for the first time that crop pollination is dependent on both honeybees and wild bees. Evenness was the best predictor of strawberry fruit weight. Shannon-diversity, species richness and abundance were less important. However, Evenness was positively related to fruit weight at the edge and negatively in the centre. This pattern was driven by the most abundant bee species, A. mellifera. Increasing proportions of A. mellifera resulted in decreasing Evenness due to its high abundances. The contrasting influence of Evenness on fruit weight between field positions appeared to be due to the changing proportions of heterospecific pollen collected by $A$. mellifera, preventing consistent pollination success (Morales \& Traveset 2008; Mitchell et al. 2009; Muchhala \& Thomson 2012). Context-dependency of Evenness versus dominance by honeybees on crop pollination has not been reported so far.

Relationships between Evenness and ecosystem processes have been scarcely analysed and have mainly been shown for the productivity and functional diversity of natural ecosystems (Hillebrand, Bennett \& Cadotte 2008; Crowder et al. 2012). However, in our study effects of Evenness appeared to rely on complementarity effects of wild bees benefitting strawberry pollination at the field edge, whereas beneficial effects of honeybee dominance at the field centre gave evidence for species identity effects.

Why $\operatorname{did}$ A. mellifera have contrasting effects on yield between field edge and centre? Such effects could result from variation in pollen loads between field locations. Interestingly, the proportion of strawberry (conspecific) pollen carried by A. mellifera increased with distance to the field edge. In the field centre, increasing proportions of A. mellifera were positively related to pollination and thus fruit 
weight. Higher importance of honeybees towards the field centre led to weaker or negative effects of Evenness. Foraging by A. mellifera in crop fields is often conducted along crop rows (Pyke 1978; Cresswell 1995), which avoids the revisiting of flowers. In the current study, bees may have started foraging at the field edge and continued along strawberry rows until the field centre. Thus having visited more strawberry flowers by the time they reach flowers at the field centre than at the field edge. In general, A. mellifera carried high percentages of strawberry pollen, which revealed high constancy to strawberry flowers. The flower constancy of $A$. mellifera is known to be influenced by other foraging resources than the target one (Wells \& Wells 1986). A. mellifera is able to change flower constancy and foraging patterns due to changing environmental conditions (Well \& Wells 1984, 1986), which can cause heterospecific pollen placement and reduce the productivity and fitness of plants (Morales \& Traveset 2008; Mitchell et al. 2009; Muchhala \& Thomson 2012). In strawberry, even small numbers of unfertilized achenes might lead to malformations and a significantly decreased fruit weight (Free 1993). Hence, the higher proportions of strawberry pollen picked up en route to flowers in the field centre would be likely to make A. mellifera more efficient pollinators at central locations, and less efficient pollinators at the field edge, where conspecific pollen loads were low.

Wild bees seem to improve pollination at the field edge, resulting in similar fruit weights compared to the other field positions. In general, wild bees have been found to be more efficient pollinators than honeybees (Parker, Batra \& Tependino 1987, Torchio 1990, Richards 1996, Klein et al. 2003, Kremen et al. 2004, Greenleaf 2006, Bosch, Kemp \& Trostle 2006; Tuell, Ascher \& Isaacs 2009; Breeze et al. 2011; Holzschuh, Dudenhöffer \& Tscharntke 2012) for various reasons as better 
performance in pollen exchange, transfer and deposition as well as interspecific interactions with honeybees (Holzschuh et al. 2012). However, these findings cannot be directly related to all crops, because the pollination success of honey bees is dependent on flower morphology (Wilson \& Thomson 1991) and honeybees are known to be equally efficient strawberry pollinators as wild bees (Albano et al. 2009), which is further suggested by similar fruit weights at all field positions. In general, Evenness and diversity are important for the stability and performance of ecosystem services (Hillebrand et al. 2008). Our results showed that strawberries were pollinated by an uneven bee community, with $A$. mellifera being most abundant at all field positions. Especially in dominated bee communities, a poor performance of the dominating species lead to a higher importance of Evenness and also diversity for the efficiency of the pollination service (Hillebrand et al. 2008; Bommarco et al. 2011). Thus, higher amounts of heterospecific pollen, carried by $A$. mellifera at the field edge suggests an inferior pollination efficiency and could have resulted in a better performance of more even and diverse wild bee communities.

CONCLUSIONS. In conclusion, our results show that A. mellifera and wild bees are both important for strawberry pollination on commercial fields, but their pollination success appears to be dependent on field positions. This finding provides a new perspective on the current debate on whether honeybees or wild bees are the most important pollinators (Ollerton et al. 2012; Aebi et al. 2012). Further, contrary to assumptions of other studies (Ghazoul 2005), pollination services cannot be sustained by a few generalist species. Our results suggest that declining populations of either bee group can have serious impacts on the overall pollination and the yield 
of strawberries. Bee abundance, species richness and Shannon-diversity that are usually expected to be good predictors of crop pollination (e.g. Cardinale et al. 2006), were much worse predictors of strawberry yield than Evenness. Future pollination studies should take potential effects of the environmental context into account, including the location inside fields. Rather than the traditional focus on pollinator abundance and species richness, community composition and Evenness should be considered as a major driver of pollination. Agricultural management policies will have to mitigate threats to all pollinator species to maintain future pollination services across the heterogeneity of crop fields.

ACKNOWLEDGEMENTS. The authors thank M. Ludwig, B. Jünemann and S. Schiele for their essential assistance in the field. We thank M. von Fragstein and G. Everwand for comments and discussions on the manuscript. This work has been funded by the German Research Foundation (DFG; TS 45/29-1).

\section{REFERENCES}

Abrol, D.P. (1992) Energetics of nectar production in some strawberry cultivars as a predictor of floral choice by honeybees. Journal of Biosciences, 17, 41-44.

Aebi, A., Vaissiere, B.E., Van Engelsdorp, D., Delaplane, K.S., Roubik, D.W. \& Neumann, P. (2012) Back to the future: Apis versus non-Apis pollination. Trends in Ecology and Evolution, 27, 142-143.

Albano, S., Salvado, E., Duarte, S., Mexia, A. \& Borges, P.A.V. (2009) Pollination effectiveness of different strawberry floral visitors in Ribatejo, Portugal: 
selection of potential pollinators. Part 2. Advances in Horticultural Science, 23, 246-253.

Barton, K. (2009) MuMIn: Multi-Model Inference. R package version 0.12.2/r18, http://R-Forge.R-project.org/projects/mumin/.

Bommarco, R., Lundin, O., Smith, H.G. \& Rundlöf, M. (2011) Drastic historic shifts in bumble-bee community composition in Sweden. Proceedings of the Royal Society London B-Biological Sciences, 279, 309-315.

Bosch, J., Kemp, W.P. \& Trostle, G.E. (2006) Bee population returns and cherry yields in an orchard pollinated with Osmia lignaria (Hymenoptera: Megachilidae). Journal of Economic Entomology, 99, 408-413.

Breeze, T.D., Bailey, A.P., Balcombe, K.G. \& Potts, S.G. (2011) Pollination services in the UK: How important are honeybees? Agriculture, Ecosystems and Environment, 142, 137-143.

Burnham, K.P. \& Anderson, D.R. (2002) Model selection and multimodel inference: a practical information-theoretic approach. Springer Verlag, New York, NY, USA.

Cardinale, B.J., Srivastava, D.S., Duffy, J.E., Wright, J.P., Downing, A.L., Sankaran, M., \& Jouseau, C. (2006) Effects of biodiversity on the functioning of trophic groups andecosystems. Nature, 443, 989-992.

Chagnon, M., Gingras, J. \& de Oliveira, D. (1993) Complementary aspects of strawberry pollination by honey and indigenous bees (Hymenoptera). Journal of Economic Entomology, 86, 416-420.

Corbet, S. A. (1991a) Applied pollination ecology. Trends in Ecology and Evolution, 6, 3-4. 
Corbet, S. A. (1991b) Honeybees forever - reply. Trends in Ecology and Evolution, 6, 338-338.

Cresswell, J.E., Bossom, A.P., Bell, S.A., Collins, S.J. \& Kelly, T.B. (1995) Predicted pollendispersal by honeybees and three species of bumblebees foraging on oilseed rape: a comparison of three models. Functional Ecology, 9, 829-841.

Crowder, D.W., Northfield, T.D., Strand, M.R. \& Snyder, W.E. (2010) Organic agriculture promotes evenness and natural pest control. Nature, 466, 109-112.

Dötterl, S. \& Vereecken, N.J. (2010) The chemical ecology and evolution of beeflower interactions: a review and perspectives. Canadian Journal of Zoology, 88, 668-697.

Free, J.B. (1993) Insect Pollination of Crops. Academic Press, London, UK.

Ghazoul, J. (2005) Buzziness as usual? Questioning the global pollination crisis. Trends in Ecology and Evolution, 20, 367-373.

Greenleaf, S.S. \& Kremen, C. (2006) Wild bee species increase tomato production and respond differently to surrounding land use in Nothern California. Biological Conservation, 133, 81-87.

Hillebrand, H., Bennett, D.M. \& Cadotte, M.W. (2008) Consequences of dominance: a review of evenness effects on local and regional ecosystem processes. Ecology, 89, 1510-1520.

Hoehn, P., Tscharntke, T., Tylianakis, J.M. \& Steffan-Dewenter, I. (2008) Functional group diversity of bee pollinators increases crop yield. Proceedings of the Royal Society London B-Biological Sciences, 275, 2283-229. 
Holzschuh, A., Dudenhöffer, J.-H., Tscharntke T. (2012) Landscapes with wild bee habitats enhance pollination, fruit set and yield of sweet cherry. Biological Conservation, 153, 101-107.

Kakutani, T., Inoue, T., Tezuka, T. \& Maeta, Y. (1993) Pollination of strawberry by stingless bee, Trigona Minangkabau, and the honey bee, Apis mellifera: an experimental study of fertilization effiency. Ressearches on Population Ecology 35, 95-111.

Klein, A.-M., Steffan-Dewenter, I. \& Tscharntke, T. (2003) Bee pollination and fruit set of Coffea arabica and C. canephora (Rubiaceae). American Journal of Botany, 90, 153-157.

Klein, A.-M., Vaissiere, B.E., Cane, J.H., Steffan-Dewenter, I., Cunningham S.A., Kremen, C., Tscharntke, T. (2007) Importance of pollinators in changing landscapes for world crops. Proceedings of the Royal Society London BBiological Sciences, 274, 303-313.

Kremen, C., Williams, N.M., Bugg, R.L., Fay, J.P. \& Thorp, R.W. (2004) The area requirements on an ecosystem service: crop pollination by native bee communities in California. Ecology Letters, 7, 1109-1119.

Mitchell, R.J., Flanagan, R.J., Brown, B.J., Waser, N.M. \& Karron, J.D. (2009) New frontiers in competition for pollination. Annals of Botany, 103, 1403-1413.

Morales, C.L. \& Traveset, A. (2008) Interspecific pollen transfer: magnitude, prevalence and consequences for plant fitness. Critical Reviews in Plant Sciences, 27, 221-238.

Morse, R.A. (1991) Honeybees forever. Trends in Ecology and Evolution. 1991, 6, $337-338$. 
Muchhala, N. \& Thomson, J.D. (2012) Interspecific competition in pollination systems: coststo male fitness via pollen misplacement. Functional Ecology, 26, 476-482.

Ollerton, J., Price, Armbruster, V.W.S, Memmott, J., Watts, S., Waser, N.M., Totland, Ø., Goulson, D., Alarcon, R., Stout, J.C. \& Tarrant, S. (2012) Overplaying the role of honey bees as pollinators: A comment on Aebi and Neumann (2011). Trends in Ecology and Evolution, 27, 141-142.

Parker, F.D., Batra, S.W.T. \& Tependino, V.J. (1987) New pollinators for our crops. Agricultural Zoology Reviews, 2, 279-304.

Pinheiro, J.C. \& Bates, D.M. (2002) Mixed effects models in $S$ and S-PLUS. Springer Verlag, New York, NY, USA.

Pyke, G.H. (1978) Optimal foraging: movement patterns of bumblebees between inflorescences. Theoretical Population Ecology, 13, 72-98.

R Development Core Team (2011) R: A language and environment for statistical computing. R foundation for statistical computing. http://www.R-project.org.

Richards, K.W. (1996) Comparative efficacy of bee species for pollination of legume seed crops. The conservation of bees (eds A. Matheson et al.), pp. 81103. Academic Press, London, UK.

Roubik, D.W. (1995) Pollination of cultivated plants in the tropics. Food and agriculture organization of the United Nations, Rome, Italy.

Roubik, D.W. (2002) The value of bees to the coffee harvest. Nature, 417, 708-708.

Torchio, P.F. (1990) Diversification of pollination strategies for U.S. crops. Environmental Entomololy, 19, 1649-1656. 
Tuell, J.K., Ascher, J.S. \& Isaacs, R. (2009) Wild Bees (Hymenoptera: Apoidea: Anthophila) of the Michigan highbush blueberry agroecosystem. Annals of the Entomololgical. Society of America, 102, 275-287.

Williams, N.M. \& Thomson, J.D. (2001) Pollinator quality in native bees and honey bees: comparing pollen removal and deposition on Phacelia tanacetifolia. For non-native crops, Whence the pollinators of the future? (eds K. Strickler \& J. H. Cane) pp. 163-179. Thomas Say Publications in Entomology, Lanham, MD, USA.

Wells, P.H. \& Wells, H. (1984) Can honey bees change foraging patterns? Ecological Entomology, 9, 467-473.

Wells, H. \& Wells, P.H. (1986) Optimal diet, minimal uncertainty and individual constancy in the foraging of honey bees, Apis mellifera. Journal of Animal Ecology, 55, 881-891.

Wilson, P. \& Thomson, J. (1991) Heterogeneity among floral visitors leads to discordance between removal and deposition of pollen. Ecology, 72, 15031507.

Winfree, R., Williams, N.M., Gaines, H., Ascher, J.S. \& Kremen, C. (2008) Wild bee pollinators provide the majority of crop visitation across land-use gradients in New Jersey and Pennsylvania, USA. Journal of Applied Ecology, 45, 793-802. 


\section{SUPPLEMENTARY INFORMATION}
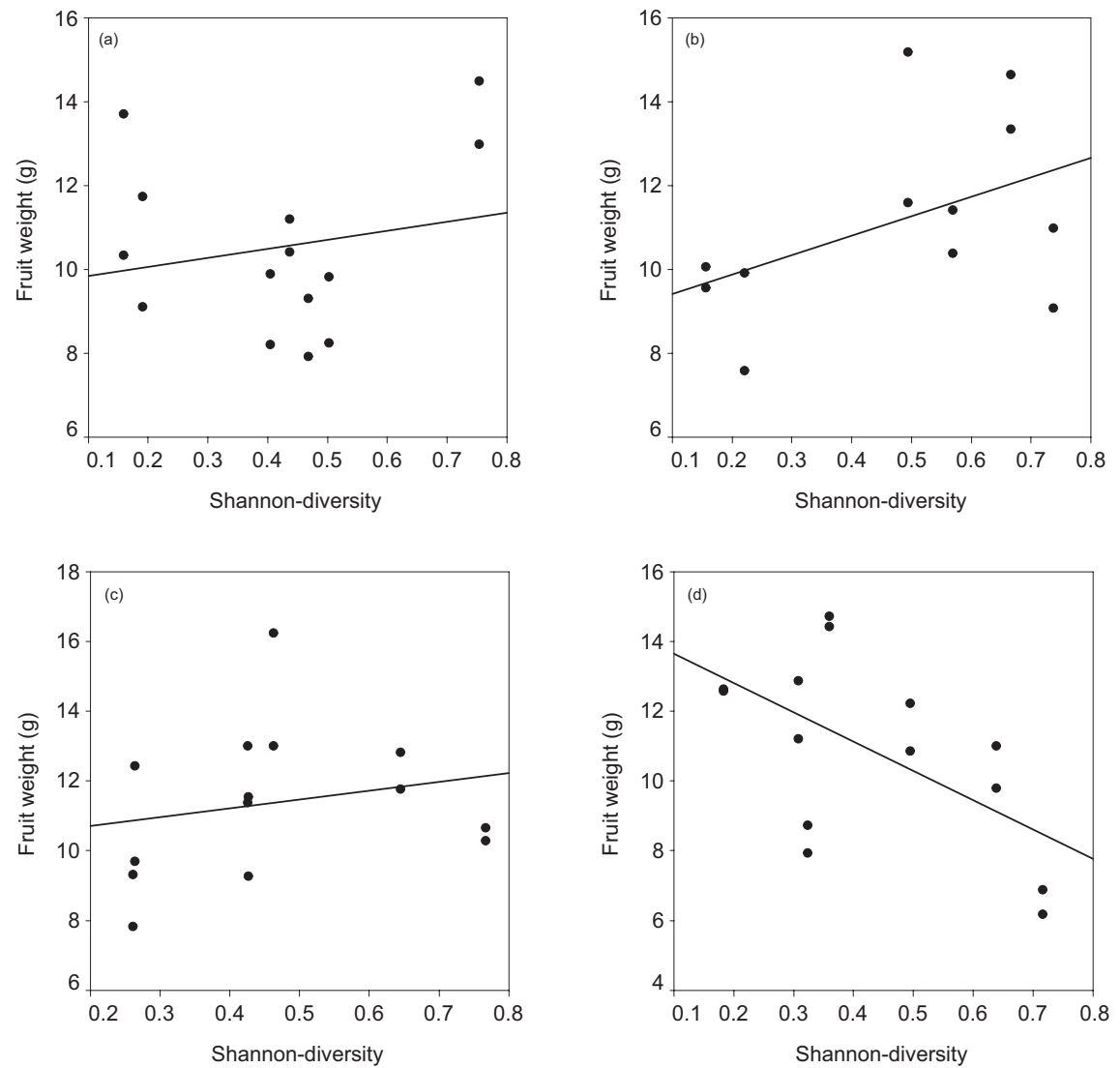

Fig. S1. Shannon-diversity of bee communities in relation to strawberry fruit weight. Effects differed between field positions (from edge to centre, i.e. field positions one to four). (a) Field position one (edge). (b) Field position two. (c) Field position three. (d) Field position four (centre). 

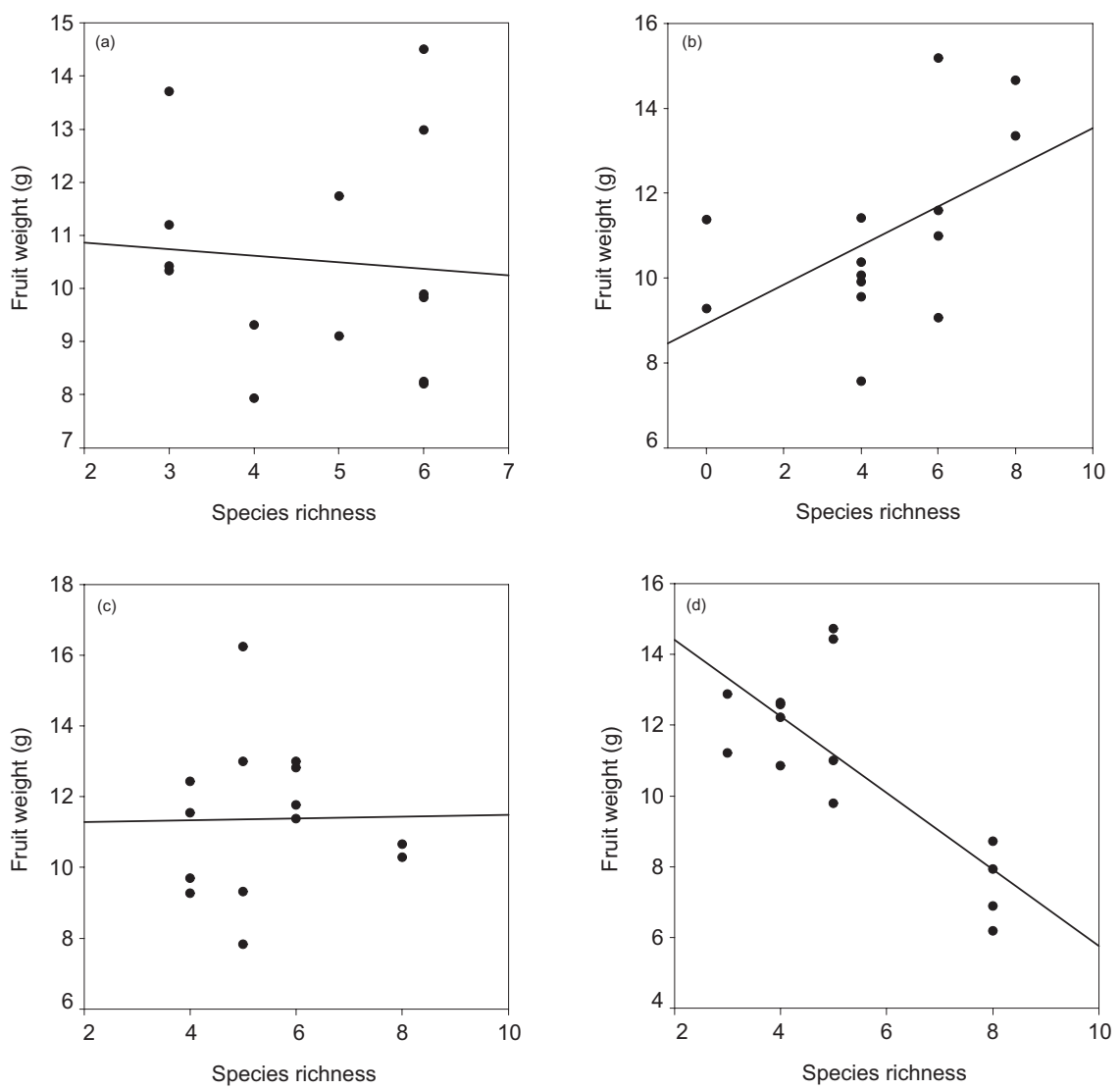

Fig. S2. Bee species richness in relation to strawberry fruit weight. Effects differed between field positions (from edge to centre, i.e. field positions one to four). Bee species richness seemed not or only slightly related to strawberry fruit weight at field positions one and three, but strongly contrasted between field positions two and four. (a) Field position one (edge). (b) Field position two. (c) Field position three. (d) Field position four (centre). 

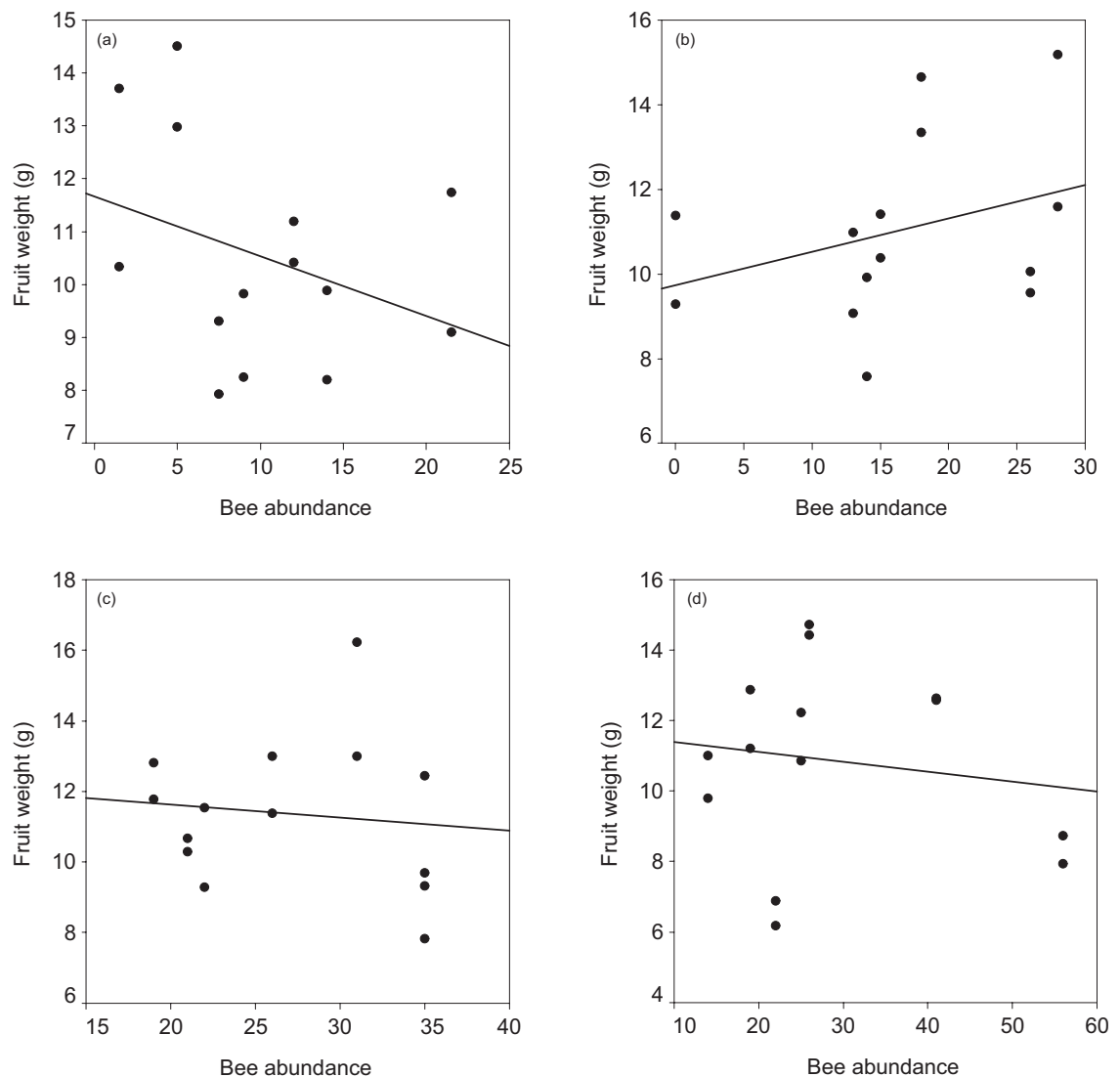

Fig. S3. Bee abundance in relation to strawberry fruit weight. Effects differed between field positions (from edge to centre, i.e. field positions one to four). Bee abundance was negatively related to strawberry fruit weight at the field positions one, three and four, but in contrast showed a positive relationship at field position two. (a) Field position one (edge). (b) Field position two. (c) Field position three. (d) Field position four (centre). 
SUMMARY. The global majority of our crops is dependent on pollination. Hence, pollination contributes to one third of global crop production and is an ecosystem service of high commercial and social importance. Bees are the most important crop pollinators, but they are endangered by several anthropogenic impacts, in particular agricultural intensification. Facing rising global demands for food and energy in the background of a growing world population, the prevention of an impending pollinator crisis attracts increasing interest from the public, policymakers and scientists. However, despite new reports on crop pollination are frequently arising, pollination research seems still at the beginning and our knowledge on crop pollination by bees at various scales is scarce.

This work aims to explore so far unknown benefits of bee pollination to highlight its overall importance. It is also focused on the main drivers of crop pollination by bees at different spatial scales, using strawberries as a study organism.

The first part (chapter 2) explores the benefits of bee pollination on commercial value and post-harvest quality of strawberry fruits from different varieties. Exclusion experiments with bee, wind and self pollination treatments were conducted on nine strawberry varieties at an experimental strawberry field. Bee pollination strongly increased the commercial value of strawberry fruits across all varieties by producing well shaped fruits with higher weight. It further elongated the shelf live of strawberries from most varieties, which was calculated from firmness values. Bee pollinated fruits had a more intense red colour and lower sugar-acid-ratios in most varieties. In general, effects differed between varieties, but with mostly similar directions. These results give a positive reply on the questions wether bee polination benefits commercial value and post-harvest quality of strawberries and the differences between varieties. 
The second part of this work (chapter 3) focused on the relationship between bee pollination and shelf life of strawberries in detail. From the first part (chapter 2), the number of fertilized achenes from fruits of the variety Yamaska was related to pollination treatments and commercial grades. In 2012, further fruits were harvested on a commercial strawberry field and divided into commercial grades in relation to malformations from insufficient pollination. The process of firmness, fruit weight and decay during storage was analysed in relation to commercial grades. During storage time, firmness and fruit weight were decreasing while the proportion of decayed fruits was increasing, independent from commercial grades. Commercial grades had a general effect on fruit degradation, with improved values in higher grades. Thus higher commercial grades resulting from improved pollination elongated the shelf life of strawberries.

Differences between varieties in part one (chapter 2) lead to the question wether strawberry varieties differ in their attraction to bees with consequences on their visitation rate (chapter 4). The influence of different volatile emissions between strawberry varieties, the bees' responses on distinct compounds and resulting visitation rates on a commercial strawberry field were analysed. Three strawberry varieties were grown in a greenhouse and the flower volatile emissions from each variety as well as anntenal responses of Osmia bicornis L. females on each compound were tested. Further the bees' visitation rates on two varieties were counted at a commercial strawberry field. All strawberry varieties emitted the same flower volatile compounds, but differed in the quantities of most of them. Anntenal reactions of $O$. bicornis females differed between most compounds and were higher than responses on controls. Under field conditions, the varietey that produced higher quantities of the most attractive compounds was visited much more frequently. 
Hence, the question about volatile emissions affecting the responses and visitation of solitary wild bees could be positively answered.

The last part of this work (chapter 5) was focused on the main drivers of various bee diversity parameters that explain the community composition of bees and their influence on strawberry fruit weight. As bee diversity is known to change related to landscape complexity, the study was conducted on commercial strawberry fields located in landscapes ranging in a gradient from homogenous to more heterogenous, to get ranging values of the bee diversity parameters. Bees were collected via sweep netting and strawberries were harvested at four field positions, that were located from field edge to center. In general, strawberry weight was strongly influenced by Evenness and to a lower level by Shannon-diversity of bee pollinators, whereas results from species richness and bee abundance were inconsistent. Higher Evenness and Shannon-diversity of the bee community improved strawberry weight at the field edge, whereas higher proportions of honeybees improved fruit weight at the field center, seemingly due to higher conspecific pollen loads. Evenness was negatively correlated to the proportion of honeybees. The research questions could be answered with Evenness being most influential on strawberry fruit weight, with contrasting effects between field locations, driven by the proportion of honeybees. In conclusion, the commercial value and post-harvest quality of strawberry fruits was strongly dependent on bee pollination, which was generally conducted by both honeybees and wild bees, but further affected by diverse scale-dependent effects. The strong relationship between fruit quantity and quality emphasizes, that pollination countervails to increasing global demands on high quality food. However, against the background of serious pollinator declines due to increasing anthropogenic impacts on various scales, pollination appears to be an ecosystem 
service that is strongly endangered, which may have extensive impacts on world food security. Hence, the results of the current work emphasize, that international conservation strategies will become more efficient by focusing on a broad scale of facets affecting crop pollination to maintain this highly important ecosystem service for the future. 


\section{ACKNOWLEDGEMENTS}

I thank my supervisers Prof. Dr. Teja Tscharntke, PD Dr. Yann Clough, Dr. Catrin Westphal and Dr. Andrea Holzschuh, for providing these highly interesting topics, various important comments, discussions and improvements during the entire time as well as for the freedom to develope own reasearch questions and experiments.

I thank Prof. Dr. Stefan Vidal for his high flexibility and being part of my defense commitee.

I kindly thank the nine farmers that permitted my research on their fields during four years. In particular I acknowledge Kay Mecke, his family and his team for being always friendly and highly flexible, thereby essentially supporting my experiments.

I thank the people of the Agroecology group for a friendly and highly creative working atmosphere. In particular my collegues and friends Dr. Maximillian von Fragstein, PD Dr. Christoph Scherber, Dr. Kristin Krewenka, Dr. Barbara Scheid, Iris Motzke, Georg Everwand, William Marty, Dr. Jochen Fründ and Dr. Thomas Wanger essentially supported this work.

Special thanks to the always friendly and highly motivated technicians of the Agroecology group, Bianca Tappe, Brigitte Jünemann and Susanne Jahn. I especially have to thank Susanne Schiele, who was one of the most principal supporters of my work due to her friendship, initiative and willingness to work for several long hours as well as creating highly motivating atmosphere and discussions the entire time. 
Last but not least I thank my family. My father and my brother for their essential assistance and several stimulating discussions about various topics. My parents and my parents-in-law for their willingness to have a sympathetic ear every time and various further support.

My greatest thanks go to the beloved, innerst circle of my family, my wife Katja and my son Alfred. Their help and support was much too manifold for specification and I thus dedicate this work to them. 


\section{PUBLICATIONS}

Klatt, B.K., Holzschuh, A., Wesphal, C., Clough, Y. Smit, I., Pawelzik, E. \& Tscharntke, T. (2013) Bee pollination improves crop quality, shelf life and commercial value. PNAS (submitted).

Klatt, B.K., Klaus, F., Westphal, C. \& Tscharntke, T. (2013) Enhancing crop shelf life with bee pollination. Journal of Applied Ecology (submitted).

Klatt, B.K., Burmeister, C., Westphal, C. \& Tscharntke, T. (2013) Flower volatiles of crop varieties and bee responses. Functional Ecology (submitted).

Klatt, B.K., Gibson, R.H., Holzschuh, A., Westphal, C. \& Tscharntke, T. (2013) Context-dependent importance of honeybee vs. wild bee pollination from crop field edges to centres. Journal of Applied Ecology (submitted). 


\section{CURRICULUM VITAE}

Dipl.-Biol. Björn K. Klatt

\section{Personal}

Position PhD candidate

Adress Agroecology

Department of Crop Sciences, University of Goettingen

Grisebachstraße 6

37077 Göttingen, Germany

Phone $\quad+49(0) 5513922057$

Mobil + +49(0)179 7007523

Fax $\quad+49(0) 551398806$

Email_klattbk@googlemail.com

Homepage http://www.uni-goettingen.de/de/215194.html

\section{Education \& experience}

Since $2009 \mathrm{PhD}$ candidate

Project: Pollination of strawberries on different spatial scales - from crop varieties and fields to landscapes

Teaching: Supervising of bachelor and master thesis, lectures, seminars

(Agroecology, Department of Crop Sciences, University of Goettingen, Germany)

$2008 \quad$ Research assistant

Project: Biodiversity Exploratories - Functional Diversity Research 
(Institute of Ecology, University of Jena, Germany)

2008

Diploma in biology with focus on ecology and landscape ecology/ climatology (Grade: 1.7)

2004-2008 Studies in biology and landscape ecology/climatology

(University of Münster, Germany; Museum of Natural History Berlin, Germany; NamibRand Nature Reserve, Namibia)

2004 Pre-diploma in biology (Grade: 1.4)

2002-2004 Studies in biology

(University of Kassel, Germany)

\section{Fields of research \& expertise}

Agroecology and landscape ecology with focus on ecosystem services on different spatial scales; influence of pollination on commercial value and post harvest-quality of crops; landscape effects on pollination and biological pest control; climate effects on pollination; pollinator attraction by flower volatile compounds; relationships between pollination and biological pest control; efficiency, competition and behaviour of bees as pollinators;

\section{Talks}

2012 4th International EcoSummit, Columbus, Ohio, USA

2012 42nd Annual Conference of the Ecological Society of Germany, Switzerland and Austria (GfÖ), Lüneburg, Germany; invited talk

2008 25. Westdeutscher Entomologentag, Düsseldorf, Germany 


\section{Periods abroad}

2007 Fieldwork at NamibRand Nature Reserve, Namibia

\section{Special education activities}

2010 Certified ArcGIS training (Grade: 1.0)

2008 Certified training for apiculturism 